\title{
Die Kontinuität der intellektuellen Tradition des Albertus Magnus: Berthold von Moosburgs Theorie des Intellekts
}

\author{
Henryk Anzulewicz \\ Albertus-Magnus-Institut, Bonn
}

Einführung

In der heute nur in zwei Handschriften aus dem 15. Jahrhundert erhaltenen Expositio super Elementationem theologicam Procli, dem ersten von den insge-

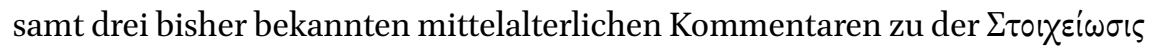

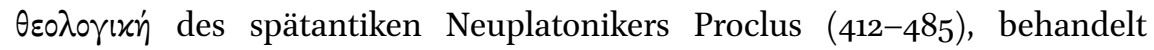
Berthold von Moosburg in seiner Exegese der Propositionen 16o-183 hauptsächlich die Intellektlehre. ${ }^{1}$ Die 24 Propositionen mit den sie begleitenden

1 Berthold von Moosburg, Expositio super Elementationem theologicam Procli. Propositiones 160-183, hg.v. U.R. Jeck, I.J. Tautz. Prolegomena und Indices hg.v. N. Bray (Hamburg: Meiner, 2003). Zu Person und Werk Bertholds cf. S. Gersh, „Berthold von Moosburg and the Content and Method of Platonic Philosophy“, in J.A. Aertsen, K. Emery, Jr., A. Speer (Hgg.), Nach der Verurteilung von 1277 (Berlin / New York: De Gruyter, 2001), S.493-503. M. Führer, S. Gersh, "Dietrich of Freiberg and Berthold of Moosburg“, in S. Gersh (Hg.), Interpreting Proclus. From Antiquity to the Renaissance (Cambridge: Cambridge University Press, 2014), S.305-317. Die lateinische Kommentartradition zu der Elementatio theologica des Proclus und zum Liber de causis, das Neuland der Mittelalterforschung, hat neuerlich D. Calma mit seinen Mitarbeitern im großen Umfang aufgearbeitet. Calma hat damit die Grundlagen für die weitergehenden, von ihm koordinierten Forschungs- und Editionsprojekte auf diesem Gebiet geschaffen. Mehrere Studien aus diesen Projekten weisen punktuelle Überschneidungen mit den Themen dieses Beitrags auf; zu nennen sind folgenden Publikationen: A. Baneu, D. Calma, „Notes sur un commentaire inédit au Liber de causis (Augsburg, Staats- und Stadtbibliothek, $4^{\circ}$ Cod. 68)“, in Bulletin de Philosophie Médiévale 54(2012), S.286-293, 295-296. D. Calma, „The Exegetical Tradition of Medieval Neoplatonism. Considerations on a Recently Discovered Corpus of Texts", in D. Calma (Hg.), Neoplatonism in the Middle Ages. I. New Commentaries on Liber de causis (ca. 1250-1350) (Turnhout: Brepols, 2016), S.3o. D. Calma, „A Medieval Companion to Aristotle: John Krosbein's Paraphrases on Liber de causis“, in D. Calma (Hg.), Neoplatonism in the Middle Ages. II. New Commentaries on Liber de causis and Elementatio theologica (ca. 1350-1500) (Turnhout: Brepols, 2016), S.11-97. F. Retucci, „Sententia Procli alti philosophi. Notes on Anonymous Commentary on Proclus' Elementatio theologica“, in Calma (Hg.), Neoplatonism in the Middle Ages. II, S.99-179. D. Calma, „Reading Proclus and the Book of Causes: Notes on the Western Scholarly Networks and Debates“, in D. Calma (Hg.), Reading 
commenta Procli bilden insofern zwei ungleiche Vorlagen für Bertholds Kommentar, als die konzisen Propositionen sowohl den eigentlichen Bezug der Exegese als auch die Grundlage für die Entfaltung von Bertholds eigener Lehren darstellen, während die Kommentare des Proclus zu den einzelnen Propositionen einer gesonderten, viel kürzeren Auslegung unterzogen werden. Beides organisiert Berthold nach einem feststehenden Muster, indem er bei der Auslegung der Propositionen, die er als das elementum bezeichnet, ${ }^{2}$ zuerst den in ihnen enthaltenen Lehrgehalt (suppositum) erschließt und in einem zweiten Schritt auf dieser Basis sein eigenes Lehrgebäude (propositum) aufbaut. Seine Auslegung der Proklischen commenta zu den einzelnen Propositionen eröffnet er mit einem syllogistischen Beweis der jeweiligen Proposition (probatio elementi) und geht anschließend zu einer nach Lemmata strukturierten Erklärung des Textes über. Bertholds Hermeneutik der inhaltlichen Erschließung der Propositionen und ihrer Beweise im Anschluss an die commenta des Proclus hat S. Gersh als einen dialektischen Dreischritt rekonstruiert. Dieser wird durch eine Erweiterung ('expansion'), eine Einschränkung ('restriktion') und eine Transformation ('alteration') der Lehrinhalte der Vorlage bei einer integralen, die Auslegung sämtlicher Propositionen einbeziehenden Lektüre des Werkes vollzogen. ${ }^{3}$ Der dritte Schritt, die Transformation, ist insofern besonders aufschlussreich, wie Gersh unterstreicht, als er Bertholds Verständnis des Platonismus und sein Verhältnis zur aristotelischen Philosophie widerspiegelt. Er verdeutlicht auch, fügen wir hinzu, die Bedeutung der durch Albert den Großen begründeten, an Pseudo-Dionysius anschließenden intellektuellen Tradition für Bertholds Auffassung der divinissima philosophia, wie sie im Einklang mit Proclus und in der Differenz zu Proclus entfaltet wird. ${ }^{4}$

Die Bindung des Kommentars an eine Textvorlage gibt naturgemäß den Rahmen für seine inhaltliche Ausgestaltung vor. Dies gilt auch für Bertholds Intellektlehre, die er in seiner Expositio super Elementationem theologicam Procli entwickelt und die im Fokus der nachfolgenden Ausführungen steht. Eine systematische Erarbeitung eines geschlossenen intellekttheoretischen Lehrstücks hat der Verfasser der weitschweifigen Expositio nicht angestrebt,

Proclus and the Book of Causes. Volume 1: Western Scholarly Networks and Debates (Leiden / Boston: Brill, 2019), S.1-13.

2 Für die etymologische Erklärung des Begriffs elementum und des Werktitels sowie des Namens des Autors siehe Gersh, „Berthold von Moosburg and the Content and Method of Platonic Philosophy“, S.498.

3 Berthold's Hermeneutik hat S. Gersh in seiner Analyse der Proposition 174 rekonstruiert, siehe Führer, Gersh, „Dietrich of Freiberg and Berthold of Moosburg“, S.310-316, insbes. S.310-311. Gersh, „Berthold von Moosburg and the Content“, S.5oo.

4 Cf. unter Anm. 28. 
da sich ihm seitens der Textvorlage ein hierfür geeigneter Ansatz offenbar nicht bot. Aus diesem Grund bildet seine Intellekttheorie auf das Ganze gesehen ein untereinander zwar vernetztes, aber auch deshalb fast nicht mehr zu durchschauendes Konglomerat verschiedener, durch die Vorlage und die verwendeten Quellen vorgegebener Elemente. Ihre Erschließung, genetische Bestimmung und Systematisierung, wie sie hier angestrebt und nur partiell durchgeführt werden kann, verlangen unter diesen Vorzeichen viel Aufwand, werfen aber einen geringen Ertrag ab, so dass ihre vollständige Aufarbeitung weiterhin ein Forschungsdesiderat bleibt. Diese Einschränkungen in Kauf nehmend wird mit Blick auf die auffälligsten Gemeinsamkeiten der Intellektlehre und der Erkenntnismetaphysik von Berthold und Albertus Magnus auf einen Bereich in einigen Punkten einzugehen sein, der bislang nicht erforscht wurde. Hierbei wird es primär um die Klassifikation der Intellekte und ihre Erklärungen gehen, um den erkenntnis-metaphysisch und existenziell aufgefassten intellektiven Aufstieg des Menschen, um Lehrinhalte, die bei Berthold einerseits systematisch konsistenter elaboriert und andererseits in der Tradition des Albertus Magnus entweder direkt oder vermittelt durch Ulrich von Straßburg und Dietrich von Freiberg verankert sind.

Die nachfolgenden Analysen der lehrinhaltlichen Koinzidenz und der suggerierten Einflüsse Alberts auf Bertholds Typologie und Interpretation der Intellekte konzentrieren sich auf seine Auslegung der Propositionen 16o, 163, 167, 174 und 181 der Elementatio theologica des Proclus. Eine erste Durchsicht des Kommentars zu den Propositionen 160-183 hat gezeigt, dass in den genannten fünf Texteinheiten Berthold sich bei seiner Proclus-Exegese und seinen intellekttheoretisch zentralen Aussagen auch der von Albert eingeführten und entfalteten Typologie und des Verständnisses der Intellekte bzw. deren Vollendungsstufen und der darauf gestützten Theorie der intellektiven Selbstüberschreitung des Menschen bedient und sie weiterentwickelt. Eine genetische Retrospektive von Bertholds Intellektlehre aus wirft Licht auf sein Verständnis der Lehre des unum animae und die epistemologische Fundierung der Mystik. Sie lässt eine nicht-reduktionistische Interpretation der Berthold'schen divinissima philosophia als eine "theologische Philosophie“ alternativlos werden, welche die gegenwärtige theologie- und philosophiehistorische Forschung, um ihre Konfundierung mit der Mystik und 'einer »Philosophie«' zu vermeiden, unter ebendiesem Namen, d.h. der "theologischen Philosophie“, zu entdecken und systematisch wiederzugewinnen begonnen hat. $^{5}$

5 Gersh, „Berthold von Moosburg and the Content“, S.499-500, und unten Anm. 3 o. 
Die zu erwägenden Fragestellungen veranlassen zunächst einen Rückblick auf die allgemeine und aktuelle Forschungslage in Bezug auf Bertholds Intellektlehre. Diskussionswürdig sind manche in der neueren Forschung prononciert vertretenen Auffassungen in Bezug auf Bertholds Grundeinstellung gegenüber der Theologie und der biblisch-christlichen Offenbarung im Besonderen, sein Selbstverständnis als Philosoph, sein Verhältnis zum kirchlichen Lehramt und zu dem sogenannten "Schularistotelismus“ einschließlich der aristotelischen Erkenntnismetaphysik. Nicht zuletzt sind die als exklusiv dargestellte Rolle Dietrich von Freibergs Philosophie, insbesondere ihre intellekttheoretischen und ethischen Ansätze zu hinterfragen, sowie die These, dass sie „als ein Fundament für jeden Interpretationsversuch des Bertholdschen Werkes betrachtet werden muß“. 6

\section{$2 \quad$ Ein Rückblick auf die Forschungen zu Berthold von Moosburg}

\subsection{Die Wiederentdeckung der Expositio super Elementationem theologicam Procli}

Der zwischen 1327 und 1361 von Berthold von Moosburg verfasste Kommentar zu der Elementatio theologica Procli geriet im Verlauf der Jahrhunderte, sofern er nicht von vornherein gemäß dem Willen des Verfassers ein verborgenes Dasein führte, in Vergessenheit und wurde erst im Jahr 1900 durch W. Rubczyński im Kodex Vat. lat. 2192 wiederentdeckt.7 Im Jahr 1926 erfolgte die Edition eines Teils des Prologs durch Raymond Klibansky, nachdem er eine zweite Handschrift von Bertholds Werk im Kodex Oxford, Balliol Coll. 224B

6 L. Sturlese, „Homo divinus. Der Prokloskommentar Bertholds von Moosburg und die Probleme der nacheckhartschen Zeit", in K. Ruh (Hg.), Abendländische Mystik im Mittelalter. Symposion Kloster Engelbert 1984 (Stuttgart: Metzlersche Verlagsbuchhandlung, 1986), S.147; repr.: „Der Prokloskommentar Bertholds von Moosburg und die philosophischen Probleme der nacheckhartschen Zeit“, in L. Sturlese, Homo divinus: Philosophische Projekte in Deutschland zwischen Meister Eckhart und Heinrich Seuse (Stuttgart: Kohlhammer, 2007), S.139.

7 W. Rubczyński, „Studia neoplatońskie“, in Przegląd Filozoficzny 3(19oo), S.41-69. H. Struve, „Die polnische Philosophie der letzten zehn Jahre (1894-1904)“, in Archiv für Geschichte der Philosophie 18(1905), S.568-571. Da Rubczyński Anknüpfungen an die von ihm wiederaufgefundene, in der Handschrift Berthold explizit zugeschriebene Expositio bei Cusanus findet und ihren Verfasser für einen Vorläufer des Cusanus hält, gibt er den Verfassernamen der Expositio in der von Cusanus überlieferten, irrtümlichen Variante mit 'Johann Mosbach' wieder. 
entdeckt hatte. ${ }^{8}$ Mit den beiden Funden und der Teilveröffentlichung, auf die im Jahr 1971 die Edition des Kommentars zu den Propositionen 49-54, die B. Faes de Mottoni ins Werk setzte, und im Jahr 1974 der erste, von L. Sturlese herausgegebene Band der historisch-kritischen Edition des Kommentars zu den Propositionen 184-211 folgten, begann die Forschung zu Berthold von Moosburg und seinem Werk. ${ }^{9}$ Sie gewann rasch an Fahrt, nachdem K. Flasch die kritische Edition des Gesamtwerkes Dietrich von Freibergs in Bochum initiiert und hierfür sowie für weitere Editionsvorhaben das Projekt eines Corpus Philosophorum Teutonicorum Medii Aevi begründet und ein internationales Forscher- und Editorenteam zur kritischen Herausgabe der Werke von Autoren, die der „Deutschen Dominikanerschule“ des 14. Jahrhunderts zugerechnet werden, gebildet hatte. Nach der Fertigstellung der kritischen Ausgabe des Gesamtwerkes Dietrich von Freibergs nahm das ursprünglich durch K. Flasch und L. Sturlese, später auch durch R. Imbach und B. Mojsisch koordinierte Editorenteam die Arbeit an der kritischen Edition Berthold von Moosburgs Expositio super Elementationem theologicam Procli auf. ${ }^{10}$ Die Edition wurde in acht Teilbänden der Bochumer Corpus Philosophorum Teutonicorum Medii Aevi-Reihe (und einem bereits 1974 in der römischen Serie Temi et Testi, Edizioni di Storia e letteratura veröffentlichten 18. Band) im Jahr 2014 vollendet.

Ein Überblick über die zurückliegende und aktuelle Forschung zu Berthold von Moosburg muss an dieser Stelle selektiv auf einige für die Fragestellung dieses Beitrags einschlägigen Untersuchungen beschränkt bleiben. Vorgestellt und im Hauptteil der Darstellung punktuell berücksichtigt werden die Pionierarbeit von W. Eckert, ${ }^{11}$ die für das Editionsprojekt und die Werkinterpretation

8 R. Klibansky, Ein Proklos-Fund und seine Bedeutung. Sitzungsberichte der Heidelberger Akademie der Wissenschaften, Philosophisch-historische Klasse, Jahrgang 1928/1929, 5 . Abhandlung (Heidelberg: Winter, 1929).

9 B. Faes de Mottoni, „Il commento di Bertoldo di Moosburg all'Elementatio theologica di Proclo. Edizione delle proposizioni riguardanti il tempo e l'eternità", in Studi medievali Ser. 3, 12(1971), S.417-461. Cf. R. Imbach, „Chronique de Philosophie: Le (néo-)platonisme médiéval, Proclus latin et l'école dominicaine allemande", in Revue de Théologie et de Philosophie 110(1978), S.437-438, 448; repr.: R. Imbach, Quodlibeta. Ausgewählte Artikel / Articles choisis, hg.v. F. Cheneval et al. (Freiburg, Schweiz: Universitätsverlag, 1996), S.149-151.

10 Cf. K. Flasch, L. Sturlese, „Vorwort“, in Berthod von Moosburg, Expositio super Elementationem theologicam Procli. Prologus, Propositiones 1-13, hg.v. M.R. Pagnoni-Sturlese, L. Sturlese (Hamburg: Meiner, 1984), S.IX-X.

11 W. Eckert, „Berthold von Moosburg O.P. Ein Vertreter der Einheitsmetaphysik im Spätmittelalter", in Philosophisches Jahrbuch 65(1957), S.120-133. 
richtungsweisende „Einleitung“ von K. Flasch ${ }^{12}$ und die sie vertiefende und weiterführende Studie von L. Sturlese. ${ }^{13}$ Thematisch zentral für die nachfolgenden Rekonstruktionen sind zwei Untersuchungen aus der Bochumer Schule, weshalb sie besondere Aufmerksamkeit auf sich ziehen. Die Erstere, bei der es sich um die Dissertation der Mitherausgeberin des intellekttheoretischen Teils der Bertholdschen Expositio, I.J. Tautz, handelt, analysiert Bertholds Intellektlehre anhand seines Kommentars zu den Propositionen $168-183 .{ }^{14}$ Die zweite Studie, ein Beitrag von B. Mojsisch zu einer Essaysammlung, bietet eine konzise Charakteristik der Intellekttheorie Bertholds und ihre Einordnung in den Gesamtkontext seines philosophischen Denkens. ${ }^{15}$ Wichtig sind ebenfalls Untersuchungen von T. Iremadze zur Erkenntnislehre und der Intellekttheorie Bertholds sowie die Studien von M.R. Pagnoni-Sturlese und A. de Libera zum Einfluss Alberts des Großen auf dessen Intellektlehre. ${ }^{16}$ Diese hier genannten einschlägigen Arbeiten und die schon herangezogenen Untersuchungen von S. Gersh werden im Hauptteil dieser Studie berücksichtigt.

\subsection{Der Beitrag von Willehad P. Eckert}

Die bedeutendsten Untersuchungen aus der frühen Phase der BertholdForschung sind die ungedruckte Dissertation von W. Eckert und sein im Philosophischen Jahrbuch unter der Überschrift „Berthold von Moosburg O.P. Ein Vertreter der Einheitsmetaphysik im Spätmittelalter" veröffentlichter

12 K. Flasch, „Einleitung“, in Berthold von Moosburg, Expositio super Elementationem theologicam Procli. Prologus. Propositiones 1-13, hg.v. M.R. Pagnoni-Sturlese, L. Sturlese (Hamburg: Meiner, 1984), S.XI-XXXVIII.

13 Sturlese, „Homo divinus. Der Prokloskommentar Bertholds“, S.145-161 (repr. S.137-154).

14 I.J. Tautz, Erst-Eines, Intellekte, Intellektualität. Eine Studie zu Berthold von Moosburg (Hamburg: Kovač, 2002).

15 B. Mojsisch, „Die Theorie des Intellekts bei Berthold von Moosburg. Zur Proklosrezeption im Mittelalter“, in Th. Kobusch, B. Mojsisch, O.F. Summerell (Hgg.), Selbst - Singularität Subjektivität. Vom Neuplatonismus zum deutschen Idealismus (Amsterdam / Philadelphia: Grüner, 2002), S.175-184.

16 T. Iremadze, „Der intellekttheoretische Ansatz der Selbstreflexivität des Denkens gemäß Kapitel 168 der Elementatio theologica des Proklos und seine Deutung sowie Entfaltung im Proklos-Kommentar Bertholds von Moosburg“, in W. Geerlings, C. Schulze (Hgg.). Der Kommentar in Antike und Mittelalter, Bd. 2: Neue Beiträge zu seiner Erforschung (Leiden / Boston: Brill, 2004), S.237-253; T. Iremadze, Konzeptionen des Denkens im Neuplatonismus. Zur Rezeption der Proklischen Philosophie im deutschen und georgischen Mittelalter: Dietrich von Freiberg - Berthold von Moosburg - Joane Petrizi (Amsterdam / Philadelphia: Grüner, 2004). M.R. Pagnoni-Sturlese, „À propos du néoplatonisme d'Albert le Grand. Aventures et mésaventures de quelques textes d'Albert dans le Commentaire sur Proclus de Berthold de Moosburg“, in Archives de Philosophie 43(1980), S.635-654. A. de Libera, La Mystique rhénane. D’Albert le Grand à Maître Eckhart (Paris: Éditions du Seuil, 1994), S.326-384. 
Aufsatz, in dem der Verfasser die wichtigsten Ergebnisse seiner in der Dissertation dargelegten Forschungen zusammenfasst. ${ }^{17}$ Er stellt den Moosburger als einen Vertreter der Einheitsmetaphysik dar und unterstreicht seine enge Beziehung zu Albert dem Großen. Diese manifestiere sich in der Expositio durch weitläufige Anleihen aus Alberts Summa theologiae, in der die Elementatio theologica des Proclus nach der lateinischen, am 12. Mai 1268 in Viterbo vollendeten Übersetzung des Wilhelm von Moerbeke erstmalig rezipiert und zitiert werde. ${ }^{18}$ Hinsichtlich der Intellektlehre beschränkt sich Eckert auf die Feststellung, Berthold habe Dietrichs Lehre vom Seelengrund übernommen. Diese wird als eine Verbindung des augustinischen Konzepts des abditum mentis mit der aristotelischen intellectus agens-Lehre begriffen. ${ }^{19}$

Mit Blick auf die später entfachte Polemik gegen Eckert's Auffassung, Berthold sei ein Vertreter der Einheitsmetaphysik, und die Verneinung des Befunds, dass Berthold's christliche Glaubensüberzeugung das hermeneutische Prinzip seines Werkverständnisses darstellt, sind zwei Aspekte hervorzuheben: Erstens, Berthold bekennt sich zur (neu-)platonischen Einheitsmetaphysik, indem er wie Platon und im Unterscheid zu Aristoteles die Priorität des Einen und/oder des Guten vor dem Sein annimmt. Am Prinzipiencharakter dieses Sein und Erkennen transzendierenden Einen bzw. des Guten ändert die Methode eines diskursiv-aufsteigenden oder eines intuitiven Zuganges nichts. ${ }^{20} \mathrm{Ob}$ Berthold sich in dieser Hinsicht von den Positionen des Meister Eckhart wesentlich unterscheidet und konsequenter als Eckhart ist, sofern das System des Letzteren sich als ein Versuch verstehen lässt, das Seinsprinzip und das Einheitsprinzip miteinander zu verbinden, wie Eckert

17 W. Eckert, Berthold von Moosburg O.P. und sein Kommentar zur Elementatio theologica des Proklos, PhD Diss. (Ludwig-Maximilians-Universität München, 1956); Eckert, „Berthold von Moosburg O.P.“, S.120-133.

18 Eckert, „Berthold von Moosburg O.P., S.127: „Die Summa theologiae Alberts des Großen schreibt er [sc. Berthold] seitenweise mitsamt ihren Zitaten aus“. Zur Rezeption der Elementatio theologica des Proclus durch Albert in seiner Summa theologiae siehe D. Siedler, P. Simon, „Prolegomena“, in Albertus Magnus, Summa theologiae sive de mirabili scientia dei, libri primi pars I, quaestiones 1-50A, hg.v. D. Siedler, W. Kübel, H.-J. Vogels (Münster i.W.: Aschendorff, 1978), S.XVI-XVII. Für die Datierung und den Ort der lateinischen, von Moerbeke angefertigten Übersetzung der Elementatio theologica siehe H. Boese, „Einleitung“, in Proclus, Elementatio theologica, translata a Guillelmo de Morbecca, hg.v. H. Boese (Leuven: Leuven University Press, 1987), S.IX.

19 Eckert, „Berthold von Moosburg O.P“, S.127. Cf. A. Colli, „Intellectus agens als abditum mentis. Die Rezeption Augustins in der Intellekttheorie Dietrichs von Freiberg“, in Theologie und Philosophie 86(2011), S.36o-371. E. Krebs, Meister Dietrich (Theodoricus Teutonicus de Vriberg). Sein Leben, seine Werke, Seine Wissenschaft (Münster i.W.: Aschendorff, 19o6), S.100.

Cf. Gersh, „Berthold von Moosburg and the Content“, S.499. 
annimmt, kann man wie bisher geteilter Ansicht sein. ${ }^{21}$ Zweitens, Berthold bekennt sich unmissverständlich zur biblisch-christlichen Offenbarung, indem er deren Lehrinhalte, darunter die innertrinitarischen Hervorgänge und Relationen sowie die Schöpfung im Rückgriff auf die pseudo-dionysische Emanationslehre und die von Proclus und von Pseudo-Dionysius inspirierte, von Albert erläuterte und von Dietrich von Freiberg entfaltete Providenzlehre zu erklären sucht und nicht zuletzt auf das Verhältnis von Theologie und Philosophie im Sinne der Auffassung von Albert und Dietrich reflektiert. ${ }^{22}$ Eine willkürliche Einwendung, Berthold wollte unter keinen Umständen ein Offenbarungstheologe sein (der er als Predigermönch ex professo war), eine Einwendung, die einen von mehreren Kritikpunkten an Eckert's Lektüre der Expositio super Elementationem theologicam Procli darstellt, erweist sich aus dieser Perspektive und aufgrund der Rolle, welche die theologischen Quellen, in erster Linie die biblischen Bücher, erfüllen, als unzutreffend. ${ }^{23}$

\subsection{Hermeneutische Neuausrichtung durch K. Flasch}

Die acht Teilbände umfassende kritische Ausgabe des Werkes Berthold von Moosburgs wird im ersten Teilband, der den Prolog und die Auslegung der Propositionen 1-13 enthält, doktrinell durch K. Flasch eingeleitet. ${ }^{24}$ Flasch beleuchtet die in Dunkel gehüllte Geschichte des Werkes von seiner Abfassung um die Mitte des 14. Jahrhundert bis zum Erscheinen der ersten Bände der kritischen Edition und revidiert die von Eckert vorgenommene philosophiesystematische Einordnung des Kommentars in die Tradition. Er bietet eine neue Interpretation der neuplatonischen Leitideen und Grundsätze dar, die das Denken des Autors bestimmen. Bertholds Hauptquellen, darunter die Rolle des Averroes, stellt er ebenso wie seine Sicht auf das Verhältnis des Autors

21 Eckert, „Berthold von Moosburg O.P.“, S.129-131.

22 Eckert, „Berthold von Moosburg O.P., S.132-133; cf. Ps.-Dionysius Areopagita, De divinis nominibus, hg.v. B.R. Suchla (Berlin / New York: De Gruyter, 199o), c. 4 n. 33, S.178 L.8-17; die lateinische Übesetzung des Johannes Sarracenus in Dionysiaca. Recueil donnant l'ensemble des traductions latines des ouvrages attribués au Denys de l'Aréopage, hg.v. Ph. Chevallier, vol. I (Brugge: de Brouwer, 1937), c. 4, S.311-313. Albertus Magnus, Super Dionysium De divinis nominibus, hg.v. P. Simon (Münster i.W.: Aschendorff 1972), c. 4 n. 224, S.298, L.4-37, S.297, L.78-84. Dietrich von Freiberg, De subiecto theologiae (fragmentum), hg.v. L. Sturlese (Hamburg: Meiner, 1983), S.279-282, bes. 3 (9), S.281, L.10o-S.282, L.109. Albertus Magnus, Commentarii in III Sententiarum, hg.v. A. Borgnet (Paris: Vivès, 1894), d. 24, a. 3, S.468a:fides et scientia sunt de eodem, non secundum idem. H. Anzulewicz, Die theologische Relevanz des Bildbegriffs und des Spiegelbildmodells in den Frühwerken des Albertus Magnus (Münster i.W.: Aschendorff, 1999), S.159. M. Roesner, Logik des Ursprungs. Vernunft und Offenbarung bei Meister Eckhart (Freiburg / München: Alber, 2017), S.101-103.

23 Siehe unten Anm. 26 und insbesondere den Beitrag von P.D. Hellmeier in diesem Band.

24 Hierzu und zum Folgenden: Flasch, „Einleitung“, S.XI-XXXVIII. 
der Expositio zur ihrer Proklischen Vorlage und zur biblisch-christlichen Offenbarungstheologie vor. Die Kritik, Korrekturen und Präzisierungen früherer Interpretationen von Bertholds Werk und philosophischem Denken bilden den Haupttenor der Einleitung. ${ }^{25} \mathrm{Zu}$ den darin dargelegten, einen bemerkenswerten Erkenntnisfortschritt markierenden Einsichten, die mit der Edition der ersten Teilbbände des Kommentars und mit der doktrinellen Erschließung des Prologs erzielt und in der Einleitung präsentiert wurden, seien einige kritische Bemerkungen angebracht. Sie beziehen sich vornehmlich auf die hermeneutisch relevanten Deutungen, die auch mit den Kritikpunkten an den von Eckert gewonnenen Erkenntnissen zusammenhängen und die für sich eine historisch mögliche, bisweilen ausschließliche, die Werkinterpretation maßgeblich bestimmende Valenz beanspruchen.

An erster Stelle seien das Ausschließen offenbarungstheologischer Elemente und Motive im Denken von Berthold und die Verneinung seines Selbstverständnisses alsTheologe zu erwähnen, die selbst beiseinem Rekurs auf die biblische Überlieferung reklamiert werden, wobei ihm auch eine dem kirchlichen Lehramt und dem „Schularistotelismus“ gegenüber kritische Attitüde attestiert wird. ${ }^{26}$ Vor dem Hintergrund von Bertholds Bezugnahmen auf die biblische und die ps.-dionysische „Epistemologie“ der Gotteserkenntnis und in Anbetracht seiner Heranziehung theologischer Autoritäten wie Ambrosius, Augustinus, Johannes von Damaskus, Maximus Confessor und Eriugena sowie philosophischer Erörterung dezidiert theologischer Fragen wie die Trinität und Schöpfung, überzeugt eine die Theologie gänzlich ausschließende Interpretation nicht. Werden indes offenbarungstheologische und philosophische Gründe und Erklärungsmuster nicht als Gegensätze sondern als korrelative, sich modal unterscheidende Interpretationen derselben Sachgehalte aufgefasst, lassen sich die dem Anschein nach unüberbrückbaren Divergenzen

25 Cf. Flasch, „Einleitung“, S.XI-XII, XIV-XV, XIX-XXI, XXV.

26 Flasch, „Einleitung“, S.XIV, insbesondere Section 3: „Es gibt weitere Selbstinterpretationen Bertholds, die zu nutzen sind. Ohne darüber zum Offenbarungstheologen werden zu wollen, intendierte er, die Invisibilia Dei durch das Geschaffene zu erkennen (Römerbrief 1,20), und interpretierte diese Erkenntnis als den intellektuellen Weg vom Abbild zum Urbild (Expos. prol. 1 Sturlese 5.5-12 u.ö.)." Andere Akzente setzt bei der Interpretation dieser Stelle Sturlese, der auf die „'propria' Gottes, d.h. die Trinität“, verweist und trotz seiner tendenziellen Enttheologisierung des Werkes Berthold unwillkürlich als Theologen ausweist; er gibt auch zu, dass Bertholds „divinissima philosophia“ als „Mystik“ bezeichnet werden kann, und charakterisiert sie als eine „deutsche Mystik“, hält aber letztlich an der Bestimmung „Philosophie“ und an der in diesem Sinne verstandenen Formel „divinissima philosophia“ fest. Schließlich räumt er ein, dass Bertholds Bestimmung dieser "göttlichsten Philosophie" als "sancta religio" sie als "Theologie“ zu bezeichnen erlaubt; cf. Sturlese, „Homo divinus. Der Prokloskommentar Bertholds“, S.153-154, 155 (repr. S.147-148, 150-151). 
auflösen. ${ }^{27}$ Gleichwohl besteht kein Zweifel, dass bei der Kommentierung dieser philosophischen Schrift ein Theologe mit einem zuhöchst philosophischen Anspruch am Werk ist, der die Gegenstände seiner Vorlage in ihrer doktrinell ursprünglichen Verankerung methodisch gerecht, d.h. ausschließlich philosophisch, sachlich jedoch nicht ohne Transformationen, Erweiterungen und Indienstnahme im Sinne seines spezifischen, in der biblisch-christlichen Offenbarungstheologie gründenden Gott- und Weltverständnisses auslegt. Er entfaltet im Anschluss an Proclus eine neue Art der "göttlichsten Philosophie“ (divinissima philosophia), die sich von jener der theologi philosophantes aus der Vorgeschichte der griechischen Philosophie wesentlich unterscheidet und, wie S. Gersh gezeigt hat, sich nicht allein auf die Proklische Theologie ohne die Berücksichtigung der sie voraussetzenden Rolle des Pseudo-Dionysius zurückführen lässt. ${ }^{28}$ Seine "theologische Philosophie" des biblisch-christlichen Zuschnitts reiht sich in die platonische Tradition von Augustinus und Boethius über Pseudo-Dionysius, Eriugena und Honorius Augustodunensis bis hin zur Albert-Schule ein, wobei neben den Dominikanern Albert dem Großen, Ulrich von Straßburg, Meister Eckhart und Dietrich von Freiberg auch der Franziskaner Thomas von York mit dem Werk Sapientiale zu den einschlägigen Quellen von Berthold's Expositio zählt. ${ }^{29}$ Es sei angemerkt, dass die

27 Cf. Sturlese, „Homo divinus. Der Prokloskommentar Bertholds“, S.149-151 (repr. S.143-145).

28 Gersh, „Berthold von Moosburg and the Content and Method of Platonic Philosophy“, S.493-503. Cf. I. Zavattero, „La figura e il pensiero di Proclo in Bertoldo die Moosburg“, in Arkete. Rivista distudifilosofici 1(2005), S.52. H. Anzulewicz, „Albertus Magnus über die philosophi theologizantes und die natürlichen Voraussetzungen postmortaler Glückseligkeit: Versuch einer Bestandsaufnahme“, in C. Steel, J. Marenbon, W. Verbeke (Hgg.), Paganism in the Middle Ages: Threat and Fascination (Leuven: Leuven University Press, 2012), S.6o-76, 8o-83. Führer, Gersh, „Dietrich of Freiberg and Berthold of Moosburg“, S.3o6317. Andere Akzente setzt in dieser Frage Sturlese, indem er die vermittelnde Rolle des Pseudo-Dionysius (dessen Werk Berthold als die Grundlage der Elementatio theologica des Proclus betrachtet haben muss) und die synthetisierende Eigenleistung des Berthold, welche die Gestalt der nostra divinalis philosophia im Sinne der christianisierten theologischen Philosophie annimmt, wenig zu beachten scheint und sich darauf konzentriert, die Rolle des Proclus und der 'Proklischen Theologie' in der Sicht Bertholds zu verabsolutisieren; cf. Sturlese, „Homo divinus. Der Prokloskommentar Bertholds“, S.15o-151 (repr. S.144145). Speziell zu der chronologischen Priorität des Pseudo-Dionysius gegenüber Proclus und dem corpus Dionysiacum als Voraussetzung, Maßstab und Garant der 'Orthodoxie' der Elementatio theologica des Proclus aus der Sicht Bertholds cf. Gersh, „Berthold von Moosburg and the Content“, S.501-502; Führer, Gersh, „Dietrich of Freiberg and Berthold of Moosburg", S.309.

29 Cf. Gersh, „Berthold von Moosburg and the Content“, S.495; de Libera, La Mystique rhénane, S.319-325. Die Bedeutung des Thomas von York als Bertholds Quelle erörtern E. King im Beitrag „Eriugenism in Berthold of Moosburg's Expositio super Elementationem theologicam Procli“, in Calma (Hg.), Reading Proclus and the Book of Causes. Volume 1, 
gegenwärtige theologie- und philosophiehistorische Forschung des christlichen und des arabisch-islamischen Kulturraumes begonnen hat, die divinissima philosophia, wie sie Berthold bezeichnete und entfaltete, unter ebendiesem Namen, d.h. der "theologischen Philosophie“, zu entdecken und systematisch wiederzugewinnen. ${ }^{30}$

Auf die kritisch gesicherte Textgrundlage des Kommentars zu den Propositionen 1-13 gestützt, lehnt Flasch die von J. Koch eingeführte Unterscheidung zwischen der neuplatonischen Einheitsmetaphysik und der aristotelischen Seinsmetaphysik sowie die Charakterisierung Bertholds als Vertreter der neuplatonischen Einheitsmetaphysik ab. Er wendet gegen diese auch durch Eckert übernommene und durch dessen eigene Forschungen bestätigte Auffassung ein und erläutert seine Position u. a. folgenderweise:

Berthold vertrat nicht eine immer schon vorhandene Einheitsmetaphysik, sondern er restaurierte um die Mitte des 14. Jahrhunderts eine durch kirchenamtliche Interventionen und den konventionellen Schularistotelismus bedrohte Tradition, deren Inhalt Berthold präzise angab: Sie betrachtete die Welt nicht nur als bewirkt und teleologisch bestimmt durch das höchste Gute, sondern sie sah sie zu ihm im Verhältnis des Akzidens zur Substanz. Diese Metaphysik des höchsten Guten wußte sich im polemischen Gegensatz zum Schularistotelismus und erhielt von daher, besonders von der im Jahre 1323 erfolgten Kanonisation des Thomas von Aquino, ihre zeitgeschichtliche Prägnanz: Sie wollte eine immanent philosophische Deutung des Weltganzen geben, unter besonderen Berücksichtigung seines dynamischen Charakters; processus und regressus der Welt wollte sie thematisieren als Ausdruck des 'ersten Guten' und der ontologischen Unselbständigkeit der 'Substanz' der Aristoteliker. Bertholds Traditionsbezug war reicher als man bisher sah;

S.408-410, und F. Retucci in ihren früheren Arbeiten (siehe King, ,Eriugenism in Berthold of Moosburg's Expositio, S.408 Anm. 44) sowie im Aufsatz „Between Cologne and Oxford: Berthold of Moosburg and Thomas of York's Sapientiale“ in diesem Band.

30 Dass Bertholds Begriff divinissima philosophia, d.h. „theologische Philosophie“, gegenwärtig keinen Anachronismus darstellt und eine Wiederbelebung erfährt, zeigen exemplarisch die Arbeiten, Lehrprogramme und Forschungsprojekte von L. Schumacher (King's College London, Department of Theology and Religious Studies), darunter insbesondere ihre Studie Theological Philosophy. Rethinking the Rationality of Christian Faith (Farnham: Ashgate, 2015). Ähnliche Entwicklung ist neuerlich auf dem Gebiet der religionsphilosophischen Forschung des Islams zu beobachten, wie exemplarisch die Essays-Sammlung von A. Shihadeh, J. Thiele (Hgg.), Philosophical Theology in Islam. Later Ash'arism East and West (Leiden: Brill 2020) belegt. 
er umfasste die averroistische Aristotelesdeutung und ihre Aktualisierung durch Dietrich ebenso wie das von Albertus Magnus genährte Interesse an Hermes Trismegistus. ${ }^{31}$

Bezüglich dieser Interpretation stellen sich einige Fragen, darunter insbesondere die, ob Berthold eine derart konsequente und gewissermaßen dialektische Vorgehensweise zuzuschreiben ist, dass er eine nur immanent philosophische Welterklärung im Ganzen geben will und kann, wenn er sich hierbei theologischer Quellen, Begriffe, Inhalte, Gründe und Muster bedient, zugleich die räumlichen Assoziationen der Aufstiegsmetapher, die als der Innbegriff der Kontingenz verstanden wird, aufhebt. ${ }^{32}$ Weisen Bertholds explizite Bezüge auf die biblische Offenbarung und seine Anlehnungen an die theologischen Autoritäten einerseits und die hermeneutische Struktur einer im Sinne der theologischen Philosophie begriffenen Deutung des Weltganzen nicht auf eine christliche Adaption eines neuplatonischen Denkmodells seines Weltverständnisses hin? Bewegt sich Berthold auf einem offenbarungstheologisch absolut freien, „immanent philosophischen“ Weg des intellektuellen Aufstiegs des Menschen von seinem göttlichen Ursprung, an dem er teilhat, zu dem wesenhaft Göttlichen und dadurch zu dem erstursächlich Guten?33

31 Flasch, „Einleitung“, S.XIV.

32 Cf. Flasch, „Einleitung“, S.xv.

33 Berthold von Moosburg, Expositio super Elementationem theologicam Procli. Prologus, hg.v. M.R. Pagnoni-Sturlese, L. Sturlese (Hamburg: Meiner, 1984), Expos. tit. L, S.49 L.408414: Comprehenditur etiam ultimo per li ELEMENTATIO THEOLOGICA finale perfectivum sive causa finalis ita, ut elementatio theologica, id est divinae rationis, importet scalarem ascensum a divinis per participationem ad divina per essentiam et per hoc ad divinum principaliforme, quod est divinum secundum causam, contemplandum; cuius contemplatione contemplator non solum efficitur beatus in assequendo 'statum omnium bonorum aggregatione perfectum, sed etiam deus. Cf. Flasch, „Einleitung“, S.XIV-XV: „Wenn man das Denken Bertholds als 'Einheitsmetaphysik' kennzeichnet, dann muß man hinzufügen: 'Einheitsmetaphysik' verstand Berthold mit Dionysius als Lehre vom höchsten Guten, mit Augustinus als Ideenlehre und Logosspekulation, mit Eriugena und wiederum mit Dionysius als Theorie der causae primordiales. Dabei legen die hier erstmals edierten Texte zwei weitere Korrekturen an dem von Josef Koch und Willehad Eckert gezeichneten Bild des 'Einheitsmetaphysikers' Berthold nahe. Beide Autoren erklärten, 'Einheitsmetaphysik' sei „immer 'Metaphysik von oben', d.h. sie geht von der absoluten Einheit als dem Erstgegebenen aus und steigt von da zum Verständnis der Welt herab. Abgesehen davon, daß kein entwickeltes philosophisches Denken sich in dieser vorstellungsorientierten Weise (Seinsmetaphysik = „Metaphysik von unten“; Einheitsmetaphysik $=$ „Metaphysik von oben“) adäquat beschreiben lässt, so trifft diese Charakteristik auf den Text Bertholds faktisch nicht zu. Wie Proklos ging Berthold vom Vielen aus, um denkend zum Einen zu gelangen [...]. Das Urbild ist nicht das Erstgegebene, sondern wir müssen, wie Berthold gleich zu Beginn seines Kommentars (Sturlese 5, 18) erklärt, durch das Abbild 
Wird dieser Weg, genauer: welcher Weg wird von Berthold konsequent durchschritten, und wird er sich für ihn am Ende, vergleichsweise wie für Albert den Großen gemäß dem Schluss seiner Schrift De intellectu et intelligibili, als zielführend erweisen? Widerspricht die Verkürzung der Metaphysik des Guten, die Berthold, Meister Eckhart und Albert entwickeln, und die Begrenzung des processus und regressus bzw. des exitus, der perfectio und der reductio, der hermeneutisch erschließenden Struktur der Seinswirklichkeit auf ein „immanent philosophisch" begreifbares Problem nicht dem onto-theologischen Charakter und Ausmaß der hier in Rede stehenden Sachgehalte? Welche Signifikanz ist der hermetischen Tradition in Bertholds Intellektlehre beizumessen, in der sie keine explizite Erwähnung findet? Die Idee der Vergöttlichung des Menschen ist nicht ausschließlich und auch nicht genuin ein hermetischer Gedanke; sie wird bei Albert nicht weniger mit den Peripatetikern als mit Hermes Trismegistus verbunden. ${ }^{34}$ Dabei ist die Tatsache zu unterstreichen, dass Berthold die Theorie der Welten und vor allem hermetische Doktrin des Menschen als Mikrokosmos wörtlich aus dem Metaphysikkommentar Alberts des Großen übernimmt, obwohl er einen viel breiteren Zugang zu dieser

zum Urbild kommen, in einer laboriosa investigatio, [...]. Doch tilgte Berthold die verräumlichenden Assoziationen dieser Metapher, indem er den Aufstieg und seine Stufen inhaltlich bestimmte als den Weg a divinis per participationem ad divina per essentiam et per hoc ad divinum principaliforme, quod est divinum secundum causam (Expos. tit. L Sturlese 49, 410-412)."

34 Cf. Albertus Magnus, De anima, hg.v. C. Stroick (Münster i.W.: Aschendorff, 1968), lib. 3, tr. 3, c. 11, S.221, L.93-S.222, L.9: et cum sic acceperit [sc. intellectus possibilis] omnia intelligibilia, habet lumen agentis ut formam sibi adhaerentem, et cum ipse sit lumen suum, eo quod lumen suum est essentia sua et non est extra ipsum, tunc adhaeret intellectus agens possibili sicut forma materiae. Et hoc sic compositum vocatur a Peripateticis intellectus adeptus et divinus; et tunc homo perfectus est ad operandum opus illud quod est opus suum, inquantum est homo, et hoc est opus, quod operatur deus, et hoc est perfecte per seipsum contemplari et intelligere separata. Albertus Magnus, De anima, lib. 3, tr. 3, c. 11, S.222, L.80-87: Mirabilis autem et optimus est iste status intellectus sic adepti; per eum enim homo fit similis quodammodo deo, eo quod potest sic operari divina et largiri sibi et aliis intellectus divinos et accipere omnia intellecta quodammodo. Haec igitur dicta sunt ad praesens de solutione istius quaestionis. Aristoteles autem distulit eam usque ad $x$ Ethicae suae ad solvendum. Die Rolle des Hermes Trismegistus im Werk Albert dem Großen beurteilt D. Porreca wesentlich zurückhaltender und kritischer als Sturlese, cf. D. Porreca, „Albertus Magnus and Hermes Trismegistus: An Update“, in Mediaeval Studies 72(2010), S.245-81. Dem Urteil von D. Porreca schließt sich J.C. Lastra Sheridan, „La influencia de los principales tópicos filosóficos del Asclepius en la obra de Alberto Magno“, in V. Buffon, C. D’Amico (Hgg.), Hermes Platonicus. Hermetismo y platonismo en el Medioevo y la Modernidad temprana (Santa Fe: Universidad Nacional del Litoral, 2016), S.127-146 an. 
Tradition durch Thomas von York hatte. ${ }^{35}$ Inwiefern aber trifft zu, dass Berthold wie Proclus nicht von Einem ausgeht, sondern von der Analyse des Vielen, welches gleichsam als Abbild begriffen wird, um zur Betrachtung des Einen, zu dem Urbild aufsteigend zu gelangen ${ }^{36}$ Legitimiert Bertholds Aussage, dass der stufenweise Aufstieg vom Göttlichen durch Teilhabe zum Göttlichen durch Wesenheit und durch dieses zum ursprünglich-formal Göttlichen, welches das Göttliche der Ursache nach ist, die bereits erwähnte Aufhebung der Aufstiegsmetapher und die totale Ablehnung der Einheitsmetaphysik, die Koch und Eckert als „Metaphysik von oben“ interpretieren?

Andere Themen aus der Forschung zu Berthold von Moosburg, die eine Neukonturierung seines individuellen philosophischen Profils bezwekken, hier aber nicht diskutiert werden können, sind für die Streitfrage des Charakters von Bertholds Metaphysik und für seine Intellekttheorie nur insofern relevant, als sie die beiden Extreme der onto-theologischen Struktur von Hervorgang und Rückkehr (processus und regressus) der Seinswirklichkeit und damit des Intellekts berühren. Albert bedient sich dieser Struktur, welche die theologische Philosophie des Neuplatonismus bereitstellt, und der peripatetischen Philosophie als des geeignetsten Werkzeugs für eine Fundierung und philosophische Explikation des Mittelstücks dieser Struktur, das ihre beiden Extreme verbindet, d.h. die raumzeitlich-materielle Ebene der Verwirklichung des Seienden. Berthold folgt Albert darin. ${ }^{37}$ Der heuristsche Nutzen aus der Anwendung dieser Struktur für die Intellektlehre, auf die Flasch nicht näher eingeht, die von Albert und Berthold im Modus der theologischen Philosophie mit einem „expansiven Optimismus“38 in Ausrichtung auf die Erkenntnis alles Intelligiblen, auf Gott als das höchste Ziel des Wissens interpretiert wird, liegt auf der Hand. In analoger Weise zu dem biblisch-christlichen Verständnis von Gott, Welt und Mensch und im Einklang mit diesem Verständnis bindet sie den Ursprung und das Ziel der menschlichen Seele und alles Seienden, den Hervorgang und die Rückkehr, an den göttlichen Ursprung als das Ziel-Prinzip, das sie als das Eine (unum) bzw. das Erste (primum) begreift und bezeichnet. Diese durch Albert vor allem in den Kommentaren zum corpus Dionysiacum

35 Cf. Iremadze, Konzeptionen des Denkens im Neuplatonismus, S.133-134. E. Ludueña, „La recepción del Asclepius en Bertoldo de Moosburg“, in Buffon, D’Amico (Hgg.), Hermes Platonicus, S.165-181; und unten Anm. 41.

$36 \quad$ Siehe oben Anm. 33 .

37 Cf. K. Flasch, „Procedere ut imago. Das Hervorgehen des Intellekts aus seinem göttlichen Grund bei Meister Dietrich, Meister Eckhart und Berthold von Moosburg“', in K. Ruh (Hg.), Abendländische Mystik im Mittelalter. Symposion Kloster Engelberg 1984 (Stuttgart: Metzler, 1986), S.125, 132.

38 Flasch, „Einleitung“, S.XVIII, XIX. 
und in De causis et processu universitatis a prima causa elaborierte und für sein theologisches wie philosophisches Denken gleichermaßen gültige und sein Verständnis der Wirklichkeit ordnende Struktur samt ihrer inhaltlichen Ausgestaltung haben Dietrich von Freiberg und Berthold von Moosburg offensichtlich inspiriert. ${ }^{39}$ Alberts Einfluss auf Berthold ist stärker als bislang angenommen und steht dem von Dietrich wenig nach, wie dies gleich verdeutlicht werden soll.

\subsection{Ausführung Kurt Flaschs Vorgaben durch Loris Sturlese}

Die Neuausrichtung der Interpretation des Werkes Berthold von Moosburgs, die Flasch in seiner Einführung eingeleitet hat, wird in einer Studie von Sturlese thematisch erweitert, vertieft und konsequent umgesetzt. ${ }^{40}$ In ihrem Fokus stehen das Verhältnis von Berthold, Proclus und Dietrich zueinander, das unum animae als die göttlichste, für Gott eigentümliche und für den Menschen mögliche Erkenntnisweise jenseits der diskursiven ratio und des Intellekts sowie die Vergöttlichung des Menschen im kontemplativem Aufstieg vom Göttlichen durch Teilhabe zum Göttlichen der Ursache nach einschließlich der hermetischen Motive der Divinisierung des Menschen, die Berthold offenkundig von Albert übernimmt. ${ }^{41}$ Den doktrinellen Einfluss Dietrichs auf Berthold, insbe-

39 Cf. H. Anzulewicz, „Die Denkstruktur des Albertus Magnus. Ihre Dekodierung und ihre Relevanz für die Begrifflichkeit und Terminlogie“, in J. Hamesse, C. Steel (Hgg.), L'Élaboration du vocabulaire philosophiques au Moyen Âge (Turnhout: Brepols, 2000), S.369-396; H. Anzulewicz, „Pseudo-Dionysius Areopagita und das Strukturprinzip des Denkens von Albert dem Großen“, in T. Boiadjiev, G. Kapriev, A. Speer (Hgg.), Die Dionysius-Rezeption im Mittelalter (Turnhout: Brepols 200o), S.251-295; H. Anzulewicz, „Hervorgang - Verwirklichung - Rückkehr. Eine neuplatonische Struktur im Denken Alberts des Großen und Dietrichs von Freiberg", in K.-H. Kandler, B. Mojsisch, N. Pohl (Hgg.), Die Gedankenwelt Dietrichs von Freiberg im Kontext seiner Zeitgenossen (Freiberg: Technische Universität Bergakademie Freiberg, 2013), S.229-244, bes. S.237-244. Flasch, „Einleitung“, S.Xv, XXıII. Flasch, „Procedere ut imago“, S.132.

40 Siehe oben Anm. 13.

41 Bertholds Inspiration durch das Werk Alberts des Großen kommt bereits im Prolog der Expositio, der ihre programmatische Outline darstellt, klar zur Geltung. Kennzeichnend und maßgeblich sind hierfür die Anleihen aus Alberts Metaphysikkommentar, welche zusammen mit den Entlehnungen aus der hermetischen Schrift des Ps.-Apuleius Asclepius - beide umrahmt durch Rm 1,20 - die hermeneutische und textuelle Grundlage (das Lemma) von Bertholds Interpretation der geschöpflichen Welt als Makrokosmos (Ps.-Apuleius) und des vergöttlichen Menschen als Mikrokosmos (Albert) bilden. Cf. Berthold von Moosburg, Expositio super Elementationem theologicam Procli, Prol. 14-19, S.23, L.57O-S.32, L.19. Albertus Magnus, Metaphysica, hg.v. B. Geyer (Münster i.W.: Aschendorff, 196o), lib. 1, tr. 1, c. 1, S.2, L.5-15. Ludueña, „La recepción del Asclepius en Bertoldo de Moosburg“, S.178-179. H. Anzulewicz, „Solus homo est nexus Dei et mundi. Albertus Magnus über den Menschen“, in S. Fernández, J. Noemi, R. Polanco (Hgg.), 
sondere auf seine Auffassung der visio beatifica und auf die Intellektlehre, stellt Sturlese radikaler als dies Flasch tat, heraus. Er meint, wie in der Einführung dieses Beitrags gleichsam als eine unabgeschlossene Frage erwähnt wurde, dass die weitgehende Übereinstimmung von Bertholds Ansichten mit denen von Dietrich „als ein Fundament für jeden Interpretationsversuch des Bertholdschen Werkes betrachtet werden muß“.42 Ohne dieser Annahme zu widersprechen, sei unterstrichen, dass die doktrinelle Nähe zu Dietrich das Interesse Bertholds an den Schriften Alberts des Großen nicht schmälerte, sondern offenkundig steigerte, zumal ihr theologisch-philosophischer Skopus und Quellenfundus weit über das Werk Dietrichs hinausreicht. Dieses Interesse Bertholds wird u.a. dadurch eindrucksvoll bestätigt, dass er mehrere Handschriften der Werke Alberts, darunter einige seiner Autographa, zur persönlichen Verfügung hatte und sie bei der Abfassung seiner Expositio als einschlägige primäre Quelle sowie als Vermittler weiterer Quellenliteratur und Ideen nutzte, wie im Fall der hermetischen Tradition und des corpus Dionysiacum erwiesen werden kann.${ }^{43}$ Er rezipierte Alberts Gedankengut auch

Multifariam. Homenaje a los profesores A. Meis, A. Bentué, S. Silva (Santiago de Chile: Pontificia Universidad Católica de Chile, 2010), S.323, 330. Bei der Auslegung der Makrokosmos- und Mikrokosmos-Lemmata zieht Berthold weitere Texte des Doctor universalis vom Anfang des Metaphysikkommentars, aus der Summa theologiae und aus De animalibus heran. Die Art und Weise der Verwendung der Schriften des Ps.-Dionysius Areopagita als Quelle des Prologs setzt einen unmittelbaren Zugriff auf das corpus Dionysiacum voraus; eine Benutzung der Dionysius-Kommentare Alberts ist allerdings, wie sich im Folgenden zeigen wird, erwiesen.

42 Siehe oben Anm. 6. Cf. Flasch, „Einleitung“, S.xxx-Xxxv.

43 In Bertholds Besitz befanden sich zwei Autographa-Handschriften Alberts mit seinen naturphilosophischen Schriften: (1) Köln, Hist. Archiv der Stadt, Codex W 258a, darin De animalibus einschließlich De natura et origine animae und De principiis motus processivi; der Codex enthält mehrere eigenhändige Vermerke von Bertholds Hand und seinen eigenhändigen Besitzvermerk, f. (I)r: „Liber fratris Bertholdi de Mosburch (darunter von einer anderen Hand: Verburch) ordinis predicatorum“. (2) Wien, ÖNB 273, darin Physica (Fragment: lib. 8 c. 2 - Ende: f. 65r-72v), De caelo et mundo, De natura loci, De causis proprietatum elementorum. Cf. W. Fauser, Die Werke des Albertus Magnus in ihrer handschriftlichen Überlieferung. Teil I: Die echten Werke (Münster i.W.: Aschendorff, 1982), S.26-27, 35, 39, 47, 143, 161, 167. E. Meyer, K. Jessen, „Appendices“, in Albertus Magnus, De vegetabilibus libri VII, hg.v. E. Meyer, K. Jessen (Berlin: Reimer, 1867), S.672-673; am Schluss des Bandes Abbildungen von De animal., f. 132r und 39or. H. Ostlender, „Die Autographe Alberts des Großen“, in H. Ostlender (Hg.), Studia Albertina. Festschrift für Bernhard Geyer zum 7o. Geburtstage (Münster i.W.: Aschendorff, 1952), S.11 und Tafel II-III am Schluss des Bandes. L. Sturlese, „Introduzione“, in Bertoldo di Moosburg, Expositio super Elementationem theologicam Procli: 184-211, De animabus, hg.v. L. Sturlese (Roma: Edizioni di Storia e Letteratura, 1974), S.XLVI-XLVII. H. Stehkämper, Albertus Magnus. Ausstellung zum 70o. Todestag [Katalog] (Köln: Historisches Archiv der Stadt, 1980), S.229 Abb. 13 und 
indirekt durch die Schriften des Dietrich und, wie M.R. Pagnoni-Sturlese aufgezeigt hat, Ulrichs von Strassburg. ${ }^{44}$ Seine besondere Wertschätzung für Albert und Dietrich kommt nicht nur durch die Nennung ihrer Namen im Verzeichnis der 'kirchlichen Gelehrten' (doctores ecclesiae) zum Ausdruck, deren Werke er bei seiner Auslegung der Elementatio theologica des Proclus benutzte. Die zweifache Erwähnung des Namens von Dietrich in der Expositio wurde unter dem Hinweis auf die seltene Praxis namentlicher Zitierung zeitgenössischer Autoren zu dieser Zeit als Ausdruck einer besonderen Ehrung und als solche als eine Ausnahme interpretiert. ${ }^{45}$ Sie ist in Wirklichkeit jedoch keine Ausnahme, denn bei der Auslegung der Proposition 118 zitiert Berthold aus der Summa theologiae I Albert des Großen unter ausdrücklicher Nennung seines Namens. ${ }^{46}$ Die Auffassung von der Sonderstellung Dietrichs erweist sich unter der genannten Hinsicht als überzeichnet und dürfte aus unserer Sicht nicht nur mit Blick auf Albert, sondern auf alle von Berthold verarbeiteten Quellen relativiert werden.

Sturlese stimmt mit Eckert hinsichtlich der Intellekttheorie des Dietrichs insofern überein, als er für Dietrich (wie Eckert für Berthold) die Vermittlung der augustinischen Auffassung des abditum mentis mit der aristotelischen intellectus agens-Lehre bescheinigt. Die Betonung, Dietrich habe „immer darauf verzichtet, in seiner Intellekttheorie die Übereinstimmung zwischen Augustin (abditum mentis) und den Aristotelikern (intellectus agens) auf die Platoniker auszudehnen“, wirft die Frage nach dem Grund dieses Verzichtes, die Dietrich nicht beantwortet. Sturlese lässt durchblicken, dass der Freiberger an der konstitutiven Funktion des Intellekts gemäß der Proposition 174 („Omnis intellectus in intelligendo instituit que post ipsum, et factio in intelligere et intelligentia in facere“) des Proclus konsequent festhält, die er kosmologisch und nicht vermögenspsychologisch auf jeden individuellen Menschen bezogen interpretiert. ${ }^{47}$ Berthold geht indes weiter als Dietrich,

14. L. Sturlese, „Note su Bertoldo di Moosburg O.P., scienziato e filosofo“, in Freiburger Zeitschrift für Philosophie und Theologie 32(1985), S.257-259.

44 Pagnoni-Sturlese, „À propos du néoplatonisme d'Albert le Grand“, S.635-654.

45 Cf. Sturlese, „Homo divinus. Der Prokloskommentar Bertholds“, S.146-147 (repr. S.139).

46 Berthold von Moosburg, Expositio super Elementationem theologicam Procli. Propositiones 108-135, hg.v. F. Retucci (Hamburg: Meiner, 2011), 118A, S.76, L.38-55.

47 Sturlese, „Homo divinus. Der Prokloskommentar Bertholds“, S.148-149 (repr. S.142). Dietrich unternimmt offenbar keinen Versuch, die systemische Inkompatibilität kosmologischer und vermögenspsychologischer Interpretationen des Intellekts vor dem Hintergrund ihrer aristotelischen und platonischen Quellen $\mathrm{zu}$ überwinden, wie Sturlese nahelegt, und vertritt somit eine nicht reduktionistische Auffassung von Differenz und Einheit der beiden Interpretationen. Einig sind sich indes Dietrich und Berthold in der Auffassung der Konvenienz der Konzepte des abditum mentis und des 
unterstreicht Sturlese, indem er die peripatetische intellectus adeptus-Lehre in die Erkenntnistheorie des Proclus integriert. Er unterscheidet außer einer zweifachen Sinneserkenntnis gemäß der äußeren und inneren Wahrnehmung und einer diskursiven sowie einer intuitiven Erkenntnis eine höhere, fünfte Stufe der menschlichen Erkenntnis, die er als die cognitio providentiae oder cognitio unialis bezeichnet. Ihren vermögenspsychologischen Grund sieht er im tätigen Intellekt (intellectus agens), sofern er zur Form des universalen Sinngehaltes des Verstandes (des intellectus possibilis gemäß der peripatetischen Begrifflichkeit) und folglich zum erworbenen Intellekt (intellectus adeptus) wird, der nach Proclus 'das Eine' (unum) unseres intellektiven Seelenteils genannt wird. Diese 'uniale Erkenntnis', der die Vereinigung des intellectus agens als Form mit dem intellectus possibilis gleichsam als die Materie zugrunde liegt, ist nach Berthold 'die göttlichste Art der Gotteserkenntnis, die qua Unwissenheit gemäß der Erkenntnis über dem Verstand gewonnen wird'48

Dreierlei Schlüsse können aus diesen Aussagen gezogen werden: Erstens, Berthold begreift die Vereinigung des intellectus agens mit dem intellectus possibilis ähnlich wie Albert der Große ontologisch als ein Eines (unum). Albert interpretiert dieses Eine als ein Kompositum aus dem intellectus agens und dem intellectus possibilis analog einer Zusammensetzung aus Form und Materie. Zweitens, Albert und Berthold bezeichnen dieses compositum bzw. unum mit den Peripatetikern als den intellectus adeptus und verstehen darunter die vom Menschen erworbene intellektuelle Vollendung, welche Berthold als die göttlichste Erkenntnis über dem Intellekt, Albert als die Gottähnlichkeit und die Vollendung der menschlichen Natur in diesem Leben interpretieren. Drittens, Berthold identifiziert den intellectus adeptus mit dem Proklischen unum animae, genauer mit dem unum ipsius partis nostrae intellectualis, einem

intellectus agens, die systemisch verschieden sind, sowie in der Zurückweisung der im Wesentlichen durch die islamisch-arabischen Philosophen vertretenen, kosmologischen Interpretation des getrennten intellectus agens. Auf diesen Konsens, auf den es im hier erörterten Zusammenhang ankommt, verweisen E. Krebs, W. Eckert und A. Colli, die eine Identifikation des intellectus agens mit dem 'Versteck' der Seele (Krebs) oder abditum mentis (Colli) für Dietrich und für Berthold (Eckert) bescheinigen; cf. oben Anm. 19. H. Anzulewicz, „De intellectu et intelligibili des Albertus Magnus: Eine Relektüre der Schrift im Licht ihrer peripatetischen Quellen", in Przeglad Tomistyczny 25(2019), S.78.

Berthold von Moosburg, Expositio, 121L, S.11o, L.172-201; 123D, S.127, L.91-S.129, l.155, esp. p 129, L.148-155; cf. Berthold von Moosburg, Expositio super Elementationem theologicam Procli, Propositiones 184-211, hg.v. L. Sturlese (Hamburg: Meiner, 2014), 197F-G, S.135, L.104-S.138, L.186. E. Massa, „La deificazione nel Commento di Bertoldo di Moosburg a Proclo, Elementatio theologica, 129. Edizione del testo e primi analisi“, in R. Lievens, E. Van Mingroot, W. Verbeke (Hgg.), Pascua Mediaevalia: Studies voor Prof. Dr.J.M. De Smet (Leuven: Leuven University Press, 1983), S.559-562. 
Konzept, das Albert zwar über Pseudo-Dionysius rezipiert, aber in seine peripatetische Intellektlehre dem exakten Begriff nach nicht integriert. Seine im Kommentarwerk De anima, lib. 3, tr. 3, c. 11, dargelegte Auffassung des intellectus adeptus nimmt Bertholds Theorie des unum animae vorweg und bildet ihre sachliche Vorlage. ${ }^{49}$ Genetisch betrachtet indes, geht das von Berthold entfaltete Konzept auf das Opusculum des Proclus De providentia (cap. 8) zurück. Diese Frage haben Massa, Sturlese und de Libera sowie zuletzt E. King hinreichend beleuchtet. ${ }^{50}$ Bertholds Kenntnis der Übernahme dieses Konzeptes durch Pseudo-Dionysius (De divinis nominibus, c. 7), die er in der Proposition ${ }_{193}$ E erläuterte, blieb offensichtlich nicht folgenlos für seine Proclus-Exegese und ihre Quellen. ${ }^{51}$

Albert der Große interpretiert in seinem Kommentar zu De divinis nominibus dieses epistemologische Konzept, welches mit den Termini unitio (gemäß der lateinischen Übersetzung des Johannes Sarracenus) bzw. unitas (nach der Übertragung des Johannes Scotus Eriugena) gekennzeichnet wird, als die aus allen Sinnen zu Einem gesammelte Kraft (virtus). Diese übersteigt die Natur des menschlichen Verstandes, vereinigt ihn in diesem Überstieg mit dem Göttlichen und macht den Menschen göttlich. Durch diese unitio soll der Mensch das Göttliche über seinem Verstand, der alles zurücklässt und sich selbst aufgibt, erkennen. ${ }^{52}$ Die uniale Erkenntnis des Göttlichen

49 Siehe oben Anm. 34. Sturlese, „Homo divinus. Der Prokloskommentar Bertholds“, S.153154 (repr. S.148-150); siehe auch die vorige Anm.

50 Massa, „La deificazione nel Commento di Bertoldo di Moosburg“, S.559-563, 570. Sturlese, „Homo divinus. Der Prokloskommentar Bertholds“, S.152-153 (repr. S.147). De Libera, $L a$ Mystique rhénane, S.331-332. E. King, „Berthold of Moosburg on Intellect and the One of the Soul“, in Dionysius 36(2018), S.184-199, hier bes. 184-186, 191-195, 198-199. Cf. Proclus, De providentia et fato et eo quod in nobis ad Theodorum Mechanicum, hg.v. H. Boese, in Procli Diadochi Tria Opuscula (De providentia, Libertate, Malo) Latine Guilelmo de Moerbeka vertente et Graece ex Isaacii Sebastocratoris aliorumque scriptis collecta, hg.v. H. Boese (Berlin: De Gruyter, 196o), c. 8 (xxIv.31-32), S.139-140. W. Beierwaltes, „Der Begriff des 'unum in nobis' bei Proklos“, in P. Wilpert, W.P. Eckert (Hgg.), Die Metaphysik im Mittelalter: Ihr Ursprung und ihre Bedeutung (Berlin: De Gruyter, 1963), S.264-265.

51 Berthold von Moosburg, Expositio super Elementationem theologicam Procli, 193E, S.103, L.121-S.104, L.134.

52 Albertus Magnus, Super Dionysium De divinis nominibus, c. 7. S.341, L.64-74: Autem, idest sed, virtutem istam dico unitionem, prout scilicet in se colligitur in unum et a multis sensibus revocatur, excedentem naturam mentis nostrae, quae immixta est sensibilibus, per quam unitionem coniungitur ad ea quae sunt supra ipsam. Igitur divina, quae sunt supra mentem, oportet intelligere secundum hanc unitionem, non secundum nos, idest non secundum proportionem et mensuram mentis nostrae, sed oportet intelligere nos ipsos statutos extra nos ipsos, totos deificatos, relinquentes ea quae sunt secundum nos, et immittentes nos divinis secundum modum ipsorum, quantum possibile est. (Die nicht in Kursiv gesetzten Wörter entstammen der Kommentarvorlage Alberts). 
bzw. die unitio mit dem Göttlichen gemäß der littera Dionysii, die Berthold als die Erkenntnis des Göttlichen über dem Verstand begreift, übernimmt Albert in seine aristotelisch-peripatetische Intellekttheorie nicht, sondern er belässt sie wie seine pseudo-dionysische Vorlage als den Gegenstand der mystischen Epistemologie, deren wissenschaftssystematischer Ort die mystischen Theologie ist. ${ }^{53}$ Den fehlenden Zugriff auf die Opuscula des Proclus hat er durch das Werk des Pseudo-Dionysius sachlich weitestgehend rekompensiert. Eine Aufhebung der in erster Linie begrifflich und hinsichtlich der reflexiven Reichweite auffallenden Differenz zwischen der aristotelischperipatetischen und der Proklisch-pseudodionysischen, der philosophischen und der theologisch-mystischen Epistemologie hatte er, wie auch Berthold, nicht intendiert. Offensichtlich bestand für die beiden Denker insofern kein Widerspruch zwischen der unialen Auffassung der Erkenntnis und dem peripatetischen Verständnis der Intellektion qua intellectus adeptus, als die Erstere die Grundlage der Erkenntnis des Göttlichen über dem Verstand und der Vereinigung mit dem göttlichen Einen darstellte, die Letztere hingegen die diskursive Erkenntnis und die unter den Bedingungen der Kontingenz erworbene intellektive Vollendung des Menschen krönte. Mit seiner Interpretation des unum animae und der mystischen unio kommt Berthold der Auslegung derselben durch Albert nahe, wenn man die Letztere aus dem Blickwinkel des Kommentars zu De mystica theologia betrachtet. Da Ulrich von Straßburg Alberts Interpretation der mystischen Epistemologie des Pseudo-Dionysius qua unitio getreu wiedergibt und Meister Eckhart das 'Eine in uns' aus der Proklisch-pseudodionysischen Tradition als den 'einfaltig einen Grund der Seele' deutet, kann Sturlese schwerlich einer „Restauration der verlorenen und wiederaufgefundenen Wahrheit" durch Berthold das Wort reden. ${ }^{54}$ Tatsächlich nimmt Alberts Auffassung der intellektiven Vollendung des Menschen aufgrund der Überformung des intellectus possibilis durch den intellectus agens, die in der peripatetischer Tradition unter dem Namen des intellectus adeptus etabliert wurde, den für Meister Eckhart's und Berthold von Moosburg's zentralen Topos der Divinisierung des Menschen vorweg. ${ }^{55}$

Sturlese's Darstellung einer unmittelbaren Gottesschau, wie diese Berthold im Anschluss an seine Proklische Vorlage und an Pseudo-Dionysius

53 Cf. H. Anzulewicz, „Scientia mystica sive theologia - Alberts des Großen Begriff der Mystik“, in Roczniki Filozoficzne 63(2015), S.37-58.

54 Ulrich von Straßburg, De summo bono. Liber 2, Tractatus 5-6, hg.v. A. Beccarisi (Hamburg: Meiner, 2007), lib. 2, tr. 5, c. 2, S.11, L.93-110; zu Meister Eckhart siehe Beierwaltes, „Der Begriff des 'unum in nobis' bei Proklos“, S.264-265. Cf. Sturlese, „Homo divinus. Der Prokloskommentar Bertholds", S.152-153 (repr. S.147).

55 Cf. Albertus Magnus, De anima, lib. 3, tr. 3, c. 11, S.222, L.4-5. 
interpretiert, erscheint aus zwei Gründen als kritikwürdig. Zum einen gibt sie zwar allgemein einen Zusammenhang der Expositio des Berthold mit den Kommentaren Alberts des Großen zum corpus Dionysiacum zu, aber sie lässt deren Vorbildfunktion und Einfluss beinahe gänzlich außer Acht. Zum andern verneint sie apodiktisch, abgesehen von einer einzigen Ausnahme, die Präsenz jeglicher offenbarungstheologisch-christlichen Motive in der Expositio. ${ }^{56}$ In Alberts Verständnis führt die analytische Methode der Wissenschaft über die Gottesnamen und dieselbe Methode der mystischen Theologie zu der Erkenntnis der Ursache, insofern diese ihren Effekt (causatum) auf univoke Weise hervorbringt bzw. aufgrund der Erhabenheit (eminentia) als Ursache unbekannt ist. ${ }^{57}$ Sie liefert die Erkenntnis der Existenz Gottes (quia), aber keine begrifflich-definitorische Erkenntnis der Wesenheit Gottes (quid und propter quia).$^{58}$ Wird die unmittelbare Gottesschau als eine Gotteserkenntnis bezeichnet und in Verbindung mit der Intellektlehre reflektiert, wie dies insbesondere für Dietrich von Freiberg gilt, ist zu bedenken, dass diese 'Erkenntnis' nach Albert und Berthold (sowie auch nach Proclus) in strengem Sinne keine intellektive Tätigkeit mehr ist, sondern ihr Endziel, mit Bertholds Worten die cognitio patriae. ${ }^{59}$ Albert beschreibt sie im Anschluss an Pseudo-Dionysius als die Verstandesnatur übersteigende Vereinigung mit Gott (unitio excedens mentis naturam), eine 'Erkenntnis, die ihren Ort über dem Verstand hat' (cognitio, quae est supra intellectum). ${ }^{60}$ Berthold stimmt darin mit Albert unter Bezugnahme auf Pseudo-Dionysius vollkommen überein. Er instanziiert zwar die Mystik und die theologische Philosophie in ihrem Wechselbezug historisch,

56 Cf. Sturlese, „Homo divinus. Der Prokloskommentar Bertholds“, S.147 (repr. S.140): „Auch das Werk Alberts des Großen, das doch die Koordinaten zeichnete, zwischen denen sich ein großer Teil der deutschen Kultur bewegte, hatte keine vergleichbare Sprengkkraft [wie die visio beatifica und die Intellektlehre Dietrichs, H.A.]“, ferner S.149-152, bes. S.152 (repr. S.143-146, bes. S.146): „Diese flüchtigen Redewendungen stellen allerdings den einzigen Hinweis zum Thema der »besonderen Gnade« dar, der in den über zweitausend Seiten des Kommentars aufzufinden ist. An keiner Stelle ist von Sakramenten, Kirche, Offenbarung, guten Werken und Glaube die Rede. Berthold leugnete nicht die Rolle der Gnade und die freie Intervention Gottes [...]“. In der dazugehörigen Fußnote 16 (repr. 30) sieht sich Sturlese in der Konfrontation mit dem gegenteiligen Tenor einiger Texte Bertholds zur Einschränkung oder vielmehr zur Rechtfertigung seiner Aussage gezwungen. Die angeblich im Werk nicht vorhandenen und dennoch durch Bertholds Texte ausgewiesenen Theologumena interpretiert er tendenziell gegen ihren für die theologische Philosophie eigentümlichen, zweifellos univoken Sinngehalt und damit gegen das Verständnis und die Intention des Autors.

57 Albertus Magnus, Super Dionysium De divinis nominibus, c. 1, S.3, L.1-15.

58 Albertus Magnus, Super Dionysium De divinis nominibus, c. 1, S.2, L.51-56.

59 Cf. Berthold von Moosburg, Expositio, 202B, S.185, L.127-137.

6o Cf. oben Anm. $5^{2}$ und 53 . 
wie Sturlese festhält, doch im Vordergrund steht letztendlich die Aufhebung der Historizität und die Andersheit der auf dem investigativen Weg erlangten Erkenntnis des Einen in seiner unmittelbaren Anschauung und in Vereinigung mit ihm. Er begreift sie wie Albert im Anschluss an Pseudo-Dionysius als „eine Erkenntnis durch Unwissenheit über dem Verstand, wenn er alles aufgibt und, sich selbst zurückgelassen, mit überstrahlender Herrlichkeit Gottes geeint, durch unergründliche Weisheit erleuchtet ist" ${ }^{\prime \prime 1}$ Als der Aufstiegsweg des menschlichen Verstandes vom Göttlichen durch Teilhabe durch Göttliches der Wesenheit nach zum Göttlichen gemäß der Ursache und zur Vergöttlichung des Menschen erhält die Theologie bzw. die theologische Philosophie des Proclus bei Albert durch die Vermittlung des Pseudo-Dionysius und bei Berthold in dessen Auslegung der Proklischen Elementatio theologica einen mystischen Charakterzug, der den heuristischen Horizont der aristotelischen Tradition transzendiert. ${ }^{62}$

Die Bestimmung der von Berthold aufgearbeiteten theologischen Philosophie des Proclus als eine philosophische Offenbarung und die Charakterisierung des Proclus als einen philosophischen Propheten bergen in sich gewisse Verständnisschwierigkeiten, die durch die bisherige Forschung offenbar nicht aufgelöst wurden. Wann und inwiefern ist ein philosophisches System als eine philosophische Offenbarung zu begreifen? Gründet die theologische Philosophie, die sich durch die ratio ausweist, in einer Offenbarung? Was macht einen philosophischen Propheten aus? Ist es nicht die besondere Gabe, theologisch gewendet Gnade Gottes, von denen Berthold in der Auslegung der Propositionen $129 \mathrm{~F}$ und 202 spricht? Können die Elementatio theologica und die Opuscula des Proclus als eine Beschreibung eines philosophie-immanenten, systemisch im Neuplatonismus verankerten Lebensentwurfs als Hervorgang, Verwirklichung im Sinne einer existenziellen Vollendung und Rückkehr des Seienden zu jenem Einen, welches das Ursprungs- und Zielprinzip zugleich von allem ist, gelesen werden? Berthold las sie als die 'Theorie des Einen' und vermochte darin eine offenbarungstheologisch konforme, wesentlich auf die Intellekttheorie bis hin zu der „divinissima cognitio Dei, quae est per ignorantiam cognita secundum unitionem super mentem" gestützte theologische

61 Berthold von Moosburg, Expositio, 123D, S.129, L.152-155ः „Haec est 'divinissima Dei cognitio, quae est per ignorantiam cognita secundum cognitionem super mentem, quando mens ab aliis omnibus recedens, postea et se ipsam dimittens unita est supersplendentibus radiis

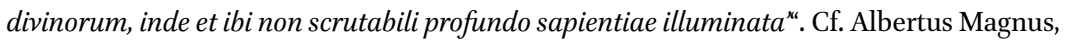
Super Dionysium De divinis nominibus, c. 7, S.359, L.42-56.75-78.

62 Cf. B. Mojsisch, „Dynamik der Vernunft bei Dietrich von Freiberg und Meister Eckhart“, in K. Ruh (Hg.), Abendländische Mystik im Mittelalter. Symposion Kloster Engelbert 1984 (Stuttgart: Metzlersche Verlagsbuchhandlung, 1986), S.138-139. 
Philosophie zu erkennen und sich zu ihr zu bekennen ${ }^{63}$ - so viel kann man aus Sturleses tiefgründigen Ausführungen entnehmen. Die Antwort auf die vorausgeschickten Fragen bieten sie nicht. Sie findet sich bei Albert in seiner Summa theologiae I und, wie man ihr entnehmen kann, gibt sie der von Sturlese und Flasch vertretenen Auffassung, für die sie keine Begründung liefern, im Wesentlichen Recht:

dicendum, quod duo modi sunt revelationis. Unus modus est per lumen connaturale nobis. Et hoc modo revelatum est philosophis. Hoc enim lumen non potest esse nisi a primo lumine dei, ut dicit Augustinus in libro De magistro, et hoc optime probatum est in Libro de causis. Aliud lumen est ad supermundana contuenda, et hoc est elevatum super nos. Et hoc lumine revelata est haec scientia. Primum relucet in per se notis, secundum autem in fidei articulis. ${ }^{64}$

(man muss sagen, dass es zwei Arten der Offenbarung gibt. Die eine Art geschieht durch das uns natürliche Licht [des Verstandes]. Auf diese Weise ist es den Philosophen offenbart worden. Denn dieses Licht kann nur vom ersten Licht Gottes sein, wie Augustinus im Buch «Über den Lehrer» sagt; und den besten Beweis für dieses Licht bietet das «Buch von den Ursachen». Ein anderes Licht gibt es zur Betrachtung des Göttlichen; und dieses ist emporgehoben über uns. Durch dieses Licht ist diese Wissenschaft [Theologie] geoffenbart. Das erste [Licht] widerscheint in den Dingen, die durch sich selbst bekannt sind, das zweite indes in den Glaubensartikeln.)

Albert klärt auf, wie die im erörterten Zusammenhang verwendeten, aber in ihrer eigentlichen Bedeutung nicht erläuterten und daher missverständlichen Begriffe der "philosophischen Offenbarung“, des "philosophischen Propheten“ und der „Proklischen Theologie“ bzw. "Mystik“ aus seiner Sicht zu verstehen sind. Seine Unterscheidung und ihre Erklärung helfen dem Bertholdschen Verständnis der divinissima philosophia auf die Spur zu kommen. Die von Sturlese erwogene Möglichkeit, den mit diesem Begriff verknüpften

63 Cf. Sturlese, „Homo divinus. Der Prokloskommentar Bertholds“, S.154 (repr. S.149).

64 Albertus Magnus, Summa theologiae sive de mirabili scientia dei, hg.v. D. Siedler, W. Kübel, H.-J. Vogels (Münster i.W.: Aschendorff, 1978), Iib. 1, tr. 1, q. 4, S.15, L.41-5o. Cf. Anzulewicz, "Albertus Magnus über die philosophi theologizantes", S.82. H. Jorissen, H. Anzulewicz, „Lumen naturale“, in W. Kasper et al. (Hgg.), Lexikon für Theologie und Kirche, vol. vI (Freiburg / Basel / Roma / Wien: Herder, 1997), col. 1120-21. 
Topos des homo divinus mit dem Begriff der Mystik zu kennzeichnen, löst das Problem genauso wenig wie ein willkürlicher, mit einem Verweis auf die Übereinstimmung mit Bertholds Wortwahl legitimierter Rückgriff auf einen Philosophiebegriff, der von der 'Schulphilosophie' unterschieden und dennoch „als »Philosophie«, wohl eine »divinissima philosophia«", zu bezeichnen wäre. ${ }^{65}$

\section{3}

\section{Berthold von Moosburgs Theorie des Intellekts}

\subsection{Einleitende Vorbemerkungen}

Bausteine zu seiner Theorie des Intellekts hat Berthold an vielen Stellen in seiner Expositio zusammengetragen. Den eigentlichen intellekttheoretischen Teil seines Kommentarwerkes hat er, wie eingangs dargelegt und wie er selbst vermerkt, auf die Auslegung der Propositionen 16o-183 konzentriert. ${ }^{66}$ Im Folgenden sollen die Typologien des Intellekts, die sich aus seiner Kommentierung der Propositionen 16o, 163, 167, 174 und 181 erheben lassen, vorgestellt und hinsichtlich ihrer Einbettung in die intellektuelle Tradition Alberts des Großen untersucht werden. Es sei angemerkt, dass die sekundären Quellen zu Bertholds Intellekttheorie, von denen die Untersuchungen von M.R. Pagnoni-Sturlese, A. de Libera, I.J. Tautz und B. Mojsisch zu nennen sind, ${ }^{67}$ dieses Vorhaben nur marginal unterstützen, da sie sowohl den Grundbegriffen als auch der Systematisierung von Bertholds Intellektlehre nicht nachgehen. Die Studie von Tautz, die einem Superkommentar (d.h. einem Kommentar zum Kommentar) zu den Propositionen 168-183 gleichkommt, teilt mit dieser Untersuchung zwar partiell ihre Textgrundlage, aber sie weist eine relativ geringe inhaltliche Überschneidung mit der Zielsetzung dieses Beitrags auf. M.R. Pagnoni-Sturlese verdeutlicht an einem Fallbeispiel, dass der Einfluss Alberts des Großen auf Bertholds Auffassung des allgemein wirkenden Intellekts durch Ulrich von Straßburg vermittelt wird. Die von de Libera und Mojsisch gebotenen Darstellungen der Intellekttheorie Bertholds sind sehr allgemein und auf wenige zentrale Aussagen beschränkt, da sie aber gelegentlich auf Bertholds Verhältnis zu Albert reflektieren, sind sie unter dieser Rücksicht für den Ansatz dieser Untersuchung bedeutsam. Ähnliches gilt für eine neuere

65 Sturlese, „Homo divinus. Der Prokloskommentar Bertholds“, S.155 (repr. S.15o).

66 Cf. Berthold von Moosburg, Expositio, 111B, S.20, L.5o.

67 Siehe oben Anm. 14-16. 
Studie von R. Imbach, in welcher ihr Verfasser die Bedeutung von Bertholds Werk für die mittelalterliche Metaphysik herausarbeitet. ${ }^{68}$

\subsection{Rekonstruktion}

Mit der Auslegung der 16o. Proposition, der ersten des intellekttheoretischen Teils seiner Expositio, beginnt Berthold eine durch die Proklische Vorlage vorgegebene, axiologisch aufgefasste und innerhalb der Kommentierung dieser Proposition entfaltete Typologie und Charakterisierung der «göttlichen Intellekte». Da sein Kommentar naturgemäß an die Abfolge und die Inhalte der einzelnen Propositionen gebunden ist, bleibt der eigentliche Kern seiner Erörterungen jeweils auf die Binnenstruktur der einzelnen Propositionen beschränkt. Diese wird zwar durch die Querverweise auf die thematisch einander ergänzende Propositionen und ihre Auslegung aufgebrochen, aber die Intellekttheorie Bertholds als Ganzes gewinnt dadurch keine organische Einheit und doktrinelle Geschlossenheit eines Lehrstücks. Ein solches wird offensichtlich nicht intendiert, wie sich auch beim Hinsehen auf die unterschiedlichen Typologien der Intellekte und ihre Quellen abzeichnet. Der Befund lässt jedoch keine Beliebigkeit in dieser Hinsicht erkennen, sondern vielmehr ein konsequentes Festhalten an dem Proklischen Einen als dem Konstitutionsprinzip der Differenz und Einheit, die im Ausgang von diesem und in der Rückwendung auf dieses Eine gedeutet und gleichsam als eine systemische totalitas begriffen werden. ${ }^{69}$ Diesem Ziel sind die internen Querverweise auf die Inhalte des Gesamtwerkes untergeordnet, die es innerhalb der Kommentare zu den einzelnen Propositionen gibt, die Bertholds Ausführungen kartieren und ihre inhaltliche Verwobenheit bewirken, eine Einheit, die nicht selten auch durch inhaltliche Wiederholungen und Redundanzen erkauft wird.

i. Die 16o. Proposition des Proclus definiert jeden «göttlichen Intellekt» als gleichförmig, vollkommen und als den «Erst-Intellekt», der aus sich andere Intellekte hervorbringt. ${ }^{70}$ Die Definition gibt die Pluralität und Einförmigkeit göttlicher Intellekte an und grenzt sie von einem «göttlichen Erst-Intellekt» ab. In seinem Kommentar erläutert Berthold ausführlich die Einzigkeit des

68 R. Imbach, „Au-delà de la métaphysique: Notule sur l'importance du Commentaire de Berthold de Moosburg op sur les Éléments de théologie“, in Calma (Hg.), Reading Proclus and the Book of Causes, Volume 1, S.376-393.

69 Cf. Massa, „La deificazione nel Commento di Bertoldo di Moosburg a Proclo, Elementatio theologica, 129 ", S.546.

70 Proclus, Elementatio theologica, 160, S.78, L.1-2: Omnis divinus intellectus uniformis est et perfectus et prime intellectus, a se ipso alios intellectus producens. Berthold von Moosburg, Expositio, 16o, S.3, L.2-4. Zum Begriff des Erst-Intellekts cf. Iremadze, „Der intellekttheoretische Ansatz der Selbstreflexivität des Denkens", S.241. 
«göttlichen Erst-Intellekts» und die Unterordnung der auf ihn folgenden, der Gattung oder der Art nach bestimmten Intellekte, mit anderen Worten, die Subordination aller sekundär «göttlichen Intellekte» unter den «göttlichen Erst-Intellekt».

Beim «göttlichen Erst-Intellekt» setzt Berthold seine erste Typologisierung der Intellekte an, mit welcher er eine dreistufige Hierarchie des «göttlichen Intellekts» annimmt. Die oberste Stufe dieser Ordnungsstruktur weist er dem «göttlichen Intellekt» zu, dem er wie Proclus eine universale Ursächlichkeit in Bezug auf alles Seiende beimisst. Von diesem «göttlichen Erst-Intellekt» unterscheidet er zwei Arten: erstens, einen «göttlichen Erst-Intellekt», der sich zu aller Intellektualität und zu allen Intellekten als einziger in der Weise des Ursprungs verhält und seiner Wesenheit und Ursächlichkeit nach göttlich ist; zweitens, einen vom Ersteren verschiedenen «göttlichen Erst-Intellekt», der nur zu einer gattungsmäßig oder spezifisch bestimmten Reihe des Seienden im Ursprungsverhältnis steht. ${ }^{71}$ Indem er den ersten «göttlichen Erst-Intellekt» mit Gott ausdrücklich identifiziert, seine Singularität und vollkommene Einheit hervorhebt, deutet er diesen zentralen Begriff der theologischen Philosophie seiner paganen Vorlage offenbarungstheologisch, genauer im Sinne der theologischen Philosophie der biblisch-christlichen Prägung um. ${ }^{72}$ In der Charakterisierung des «göttlichen Erst-Intellekts» als die Erstursache allen Seins und in seiner Gleichsetzung mit Gott ist eine Nähe zu Ulrich von Straßburgs Auffassung des Intellekts als Gottesname und zur Darstellung seiner Eigenschaften erkennbar, die Berthold aus der Schrift De summo bono

71 Berthold von Moosburg, Expositio, 16oA, S.3, L.14-20: triplex est divinus intellectus; ex quo enim omne, quod qualitercumque subsistit, aut secundum causam principaliformiter aut secundum existentiam aut secundum participationem subsistit per 65 [cf. Berthold von Moosburg, Expositio super Elementationem theologicam Procli. Propositiones 35-65, hg.v. A. Sannino (Hamburg: Meiner, 2001), 65, S.201, L.1-4: Omne, quod qualitercumque subsistit, aut secundum causam principaliformiter aut secundum essentiam aut secundum participationem exemplariter. Proclus, Elementatio theologica, 65, S.35, L.1-3: „Omne quod qualitercumque subsistit aut secundum causam est principaliformiter aut secundum existentiam aut secundum participationem exemplariter"]. Ideo divinus intellectus potest accipi et pro eo, qui est prime ad totam seyram intellectualitatis, qui etiam est singularis, cum sit monarcha omnium intellectuum principaliformiter subsistens in intellectualitae, licet sit divinus secundum essentiam; 16oL, S.9, L.187-19o: Ex iam dicitis apparet, quod divinum intellectum esse prime intellectum accipitur dupliciter, quia vel principaliformiter respectu totius seyrae intellectualitatis, et sic est divinus secundum essentiam et intellectus principaliformiter, scilicet secundum causam, et talis est unus tantum, vel respectu alicuius generis vel speciei determinatae intra totalitatem intellectualis seyrae conclusorum, et talis intellectus prime existens est intra ordinem intellectualium hypostasum.

72 Cf. Berthold von Moosburg, Expositio, 16oA, S.4, L.32: qui est deus per essentiam et intellectus prime. 
des Albert-Schülers, einer seinen Quellen der Expositio, vertraut war. Ulrichs Position hingegen spiegelt auch in diesem Punkt die Lehre seines Meisters Alberts des Großen und ihre Quellen wider. ${ }^{73}$

Den «göttlichen Intellekt», dem die Intellektualität an sich eignet und der eine an der Göttlichkeit teilhabende und multiplizierbare Natur ist, ordnet Berthold der zweiten Hierarchiestufe zu. Mit Verweis auf seine parallele Unterscheidung der Intellektualität, die er bei der Auslegung der Proposition 111 vornahm, schränkt er ein, dass nicht jeder «göttliche Intellekt» dieser Ordnung wesenhaft göttlich ist, obwohl er grundsätzlich zuerst und durch sich selbst seinem Wesen nach Intellekt schlechthin und göttlich gemäß der Teilhabe ist. Diesem Intellekt gilt seine Interpretation der 16o. Proposition der Proklischen Elementatio. ${ }^{74}$

Der drittletzten Stufe in der Hierarchieskala des «göttlichen Intellekts» rechnet er einen «göttlichen Intellekt» zu, der seine «göttliche» Eigenschaft durch Teilhabe an der göttlichen Einheit erlange. Er habe keine eigenständige Subsistenz einer intellektiven Hyposthase und bedürfe wie der höhere Teil der Seele einer Seinsgrundlage, deren Teil er sei. In der Rangordnung der

73 Cf. Ulrich von Straßburg, De summo bono, lib. 2, tr. 5, S.3-8. Das Werk Ulrichs, der zu den „begeistertsten und treuesten Schülern Alberts“ (Grabmann) zählte, gehört zu den von Berthold verzeichneten Quellen seiner Expositio. Außer dieser Nennung wird er, anders als im Fall von Dietrich von Freiberg und Albert dem Große, im Werk namentlich nicht zitiert, und daher bleibt sein Anteil an der Lehre Bertholds unauffällig und in der kritischen Edition relativ selten nachgewiesen. Auf seinen Einfluss auf Berthold weisen hin: M. Grabmann, „Studien über Ulrich von Straßburg“, in M. Grabmann, Mittelalterliches Geistesleben [vol. I] (München: Hueber, 1926), S.218; M. Grabmann, „Der Einfluss Alberts des Großen auf das mittelalterliche Geistesleben“, in M. Grabmann, Mittelalterliches Geistesleben, vol. II (München: Hueber, 1936), S.366; Imbach, „Chronique de Philosophie“, S.434-435 (repr. S.143-144). Pagnoni-Sturlese, „A propos du néoplatonisme d'Albert le Grand“, passim; L. Sturlese, „Proclo ed Ermete in Germania da Alberto Magno a Bertoldo di Moosburg“, in K. Flasch (Hg.), Von Meister Dietrich zu Meister Eckhart (Hamburg: Meiner, 1984), S.28; A. Beccarisi, „Einleitung“, in Ulrich von Straßburg, De summo bono. Liber 2, Tractatus 5-6, hg.v. A. Beccarisi (Hamburg: Meiner, 2007), S.viII, XIX, Xx; E. King, „Eriugenism in Berthold of Moosburg's Expositio super Elementationem theologicam Procli', S.401-403, 405, 407, 410.

74 Berthold von Moosburg, Expositio, 16oA, S.3, L.21-25: Secundo accipitur divinus intellectus pro eo, qui est intellectus secundum existentiam, scilicet primo et per se habens intellectualitatem, sed participat divinitate, et talis est plurificabilis, licet non omnis intellectus per essentiam sit divinus: Omnis enim intellectualis seyrae hi quidem divini sunt intellectus deorum suscipientes posthabitationem, hi autem intellectus solum per 11 [hg.v. Retucci, S.19, L.2-9. 27-29; hg.v. Boese, S.56, L.1-7]; S.4, L.34-36: Secundus est intellectus primo et per se per essentiam absolute et divinus secundum participationem, omnis scilicet intellectus, qui est intra ordinem intellectualium hypostasum. Et de talibus intelligo elementum. 
«göttlichen Intellekte» folgt er auf die «göttlichen Seelen». ${ }^{75}$ Diesen «göttlichen Intellekt» der drittletzten Hierarchiestufe und den erst-göttlichen Intellekt lässt Berthold bei seiner Analyse der Definition dieses Theorems aus.

Gemäß dieser ersten, sich aus dem Kommentar zu der Proposition 16o erschließendenTypologie des «göttlichenIntellekts» wird dieserdurch Berthold dreifach hierarchisch unterschieden und wie folgt näher bestimmt:

intellectus divinus

1. secundum causam principaliformiter

- prime ad totam seyram intellectualitatis

- singularis

- deus per essentiam

2. secundum existentiam

- primo et per se habens intellectualitatem

- participat divinitate

- plurificabilis

- omnis intellectus intra ordinem intellectualium hypostasum

3. secundum participationem divinae unitatis

- non habens fixionem subsistentiae suae se ipso

- innititur quodammodo sicut suprema »portio residuae substantiae animae«, cuius est pars

Was lässt sich in Bezug auf Bertholds Typologie und Interpretation des «göttlichen Intellekts», ihre Einordnung in die theologisch-philosophische Tradition und deren Verhältnis zu Albert genau ermitteln?

Es ist zunächst festzuhalten, dass der quellenkritisch auf den ersten Blick gut erschlossene Text des Kommentars in der kritischen Edition keinen Hinweis für die Existenz einer anderen Quelle der Typologie des «göttlichen Intellekts» als diese und andere Propositionen der Elementatio theologica des Proclus und Bertholds eigene Invention bei deren Auslegung gibt. Eine genetische Erschließung der Typologie leistet Berthold insofern selbst, als er bei ihrer Erläuterung auf seine identische Aufteilung und Interpretation des «göttlichen Intellekts» verweist, die er zuvor im Kommentar zur Proposition 134

75 Berthold von Moosburg, Expositio, 16oA, S.3, L.26-3o: Tertio accipitur intellectus divinus pro eo, qui est «intellectus per essentiam», licet non primo modo, qualis est divinarum animarum sive totalium sive partialium, qui etiam est divinus participatione divinae unitatis. Omnis enim intellectus divinus est huiusmodi secundum participationem divinae unitatis per tertiam partem 129 [Omnis autem intellectus divinus secundum participationem divinae unitatis: hg.v. Retucci, S.173, L.4-5; hg.v. Boese, S.65, L.2-3]. 
vornahm, welche die Erkenntnis- und Providenzweise des «göttlichen Intellekts» definiert. ${ }^{76}$ Von dort verweist er auf die Proposition 65 der Elementatio theologica des Proclus zurück, die den eigentlichen Ursprung seiner Typologie des «göttlichen Intellekts» bildet. Sie gibt die im Kommentar zu der 16o. Proposition angenommene Dreiteilung des «göttlichen Intellekts» wortwörtlich mit dem einen Unterschied wieder, dass sie formal dieselbe Unterscheidung auf die Seinsweise von allem, was auch immer existiert (omne quod qualitercumque existit), bezieht. Die eingehende und aus der Gesamtperspektive des Werkes betrachtet sich wiederholende Erläuterung der Seinsmodi der einzelnen Intellekte ist offenbar Bertholds eigene Leistung. Auf der Kommentierungsebene indes bot sich ein Raum für die Einbeziehung von Quellen und Inspirationen unterschiedlicher Traditionen und Herkunft. Diese narrativen Seiten seiner Expositio bergen in sich zumeist stillschweigende Auskünfte zu den Fragen, inwiefern er sich die intellektuelle Tradition des Albertus aneignete und schöpferisch fortführte.

Bertholds distinkter Begriff des «göttlichen Intellekts» und seine dreifache Unterscheidung rühren zwar unmittelbar aus der Proklischen Vorlage her, aber sie sind weder in Proclus' Schrift noch in der neuplatonischen Tradition exklusiv verankert. Wenn Berthold in seiner Interpretation dieses Begriffs der genuin neuplatonischen Tradition folgt, was durch die expliziten Rückverweise aus dem Kommentar zur 16o. Proposition auf eine Reihe der Proklischen Propositionen und ihre Auslegung belegt ist, ${ }^{77}$ schließt diese Tatsache nicht einen erweiterten Traditionsbezug des Kommentars aus, wie schon K. Flasch gesehen hat und wie es sich auch in diesem Fall zeigt. Dieser explizite und indirekte, in der Edition quellenkritisch nachgewiesene, erweiterte Traditionsbezug erstreckt sich im Kommentar zur Proposition 16o von Aristoteles über Ps.-Dionysius, Albertus Magnus und Dietrich von Freiberg bis hin zu den arabisch-islamischen Philosophen Avicenna und Averroes.

Will man nun Bertholds Verhältnis speziell zu Albert mit Bezug auf dessen Auffassung des «göttlichen Intellekts» charakterisieren, ist zu berücksichtigen, dass Albert sich dieses Begriffs bereits im Frühwerk bediente. Eine Strukturanalyse und Erklärung der drei unterschiedenen Intellekte hat er im Metaphysikkommentar unternommen. Im Unterschied zu Berthold gründete sein Begriffsverständnis vornehmlich im corpus Dionysiacum und im Liber

76 Berthold von Moosburg, Expositio, 134B, S.214, L.21-S.215, L.45.

77 Berthold rekurriert bei der Auslegung der Proposition 16o explizit auf folgende Propositionen bzw. Kommentare des Proclus zu den Propositionen der Elementatio (in der Reihenfolge der Verweise): 134, 65(bis), 111, 129, 110, 122, 119, 52(bis), 26, 153, 34, 64, 114, 8, 22, 75, 11, 99(bis), 131, 134, 125, 28; bei der Auslegung des Proklischen Kommentars zur Proposition 16o nimmt Berthold Bezug auf die Propositionen 18 und 97. 
de causis; die Elementatio theologica stand ihm vorerst nicht zur Verfügung. Das Bekanntwerden und die Aneignung der aristotelischen Intellektlehre einschließlich ihrer spätantiken griechischen und arabisch-islamischen Auslegung und Fortführung erweiterten sein Begriffsverständnis. Der genuin neuplatonische Begriff wurde folglich zum Bestandteil von Alberts Intellektspekulation, die unterschiedliche Traditionen amalgamierte. Diese Entwicklung nahm ihren Lauf im theologischen Frühwerk De resurrectione und De quattuor coaequaevis ${ }^{78}$ und setzte sich in den Aristoteles-Kommentaren zu De caelo et mundo, zur Physik bei der Diskussion der Unendlichkeit, zu De anima bei der Erörterung der Natur der intellektiven Seele, zur Nikomachischen Ethik und Metaphysik, wo sich gewisse Anklänge an das Proklische Verständnis finden, fort. ${ }^{79}$ In Alberts neuplatonisch inspirierten Werken De natura et origine animae und De intellectu et intelligibili, in De causis et processu universitatis

78 Albertus Magnus, De resurrectione, hg.v.W.Kübel(Münsteri.W.:Aschendorff, 1958), tr. 4q.2, a. 5, S.344, L.76-82; Albertus Magnus, De quattuor coaequaevis (Summa de creaturis pars I), hg.v. A. Borgnet (Paris: Vivès, 1895), tr. 2, q. 3, a. 2, S.345b: ideae sunt in intellectu divino. Albertus Magnus, De quattuor coaequaevis, tr. 4, q. 34, a. 1, S.522a-b: Dicit Dionysius in libro de Coelesti hierarchia, quod Archangeli Angelis communicant illuminationes, et Angeli nobis, secundum uniuscujusque illuminatorum analogiam'. Et ita videtur, quod dant nobis illuminationes, et ita faciunt in nobis intellectum divinum. Albertus Magnus, De quattuor coaequaevis, tr. 4, q. 34, a.2, S.524a: Secundo quaeritur, Per quem modum faciunt in nobis Angeli intellectum divinum? Albertus Magnus, De quattuor coaequaevis, tr. 4, q. 36, a. 2, part. 2, S.541b: Et hoc patet iterum ex hoc quod intelligentia angelica non est nisi in triplici consideratione. Cum enim in ipsa sit medium inter intellectum divinum et humanum, potest accipi in se [...]. Albertus Magnus, De quattuor coaequaevis, tr. 4 q. 53, S.593b: Et quidem omnino in participatione sapientiae et scientiae esse commune est omnibus deiformibus intellectibus. Attente autem et primo aut secundo aut infra nequaquam commune, sed sicut unicuique ante propria diffinitur analogia. Haec autem et de omnibus divinis mentibus non fortassis quis errans diffiniet. Albertus Magnus, De quattuor coaequaevis, tr. 4, q. 6o, a. 2, S.635a: Praeterea cum dicat Dionysius, quod intellectus divini per tria dividuntur, scilicet essentiam, virtutem, et operationem [...]. Albertus Magnus, De quattuor coaequaevis, tr. 4, q. 6o, a. 2, S.637b: Dionysius secundum denominationem dividit intellectus divinos in tria: quia a tribus denominantur. Dicuntur enim coelestes essentiae, et coelestes virtutes, et coelestes nuntii sive Angeli. Albertus Magnus, De quattuor coaequaevis, tr. 4, q. 67, a. 5, S.689b: quilibet intellectus illustratur ex hoc quod conjungitur superiori. Intellectus enim hominis accipit illustrationem ab intellectu Angeli, et intellectus Angeli ab illuminatione intellectus divini.

79 Cf. Albertus Magnus, Super Ethica. Commentum et quaestiones, hg.v. W. Kübel (Münster i.W. 1987), lib. 10, lect. 3, S.719, L.23: intellectualitas divina. Albertus Magnus, Super Ethica, lib. 10, lect. 11, S.752, L.74-75: quaestio de intellectu divino. Albertus Magnus, Metaphysica, lib. 1, tr. 2, c. 4, S.22 L.2-5. Albertus Magnus, Metaphysica, hg.v. B. Geyer (Münster i.W.: Aschendorff, 1964), lib. 6, tr. 2, c. 6, S.311, L.7O-71.86-87, S.312, L.20-21.25-26.44.53. Albertus Magnus, Metaphysica, lib. 7, tr. 1, c. 4, S.320, L.38. Albertus Magnus, Metaphysica, L.11, tr. 2, c. 32, S.524, L.14. 
a prima causa sowie in den theologischen Schriften, darunter De homine, die Bibelkommentare, Quaestio de prophetia, der Sentenzenkommentar und Summa theologiae, ist der Begriff stets präsent. Albert verband ihn auch mit dem Timaeus des Platon, obwohl die Bestimmung "göttlich“ (divinus) dort fehlt. ${ }^{80}$

Berthold hat sich bei der Kommentierung der Proklischen Propositionen im intellekttheoretischen Teil seines Werkes mehrerer Schriften Alberts als Quelle bedient. Einen ersten Eindruck über seine Anleihen vermitteln die entsprechenden Nachweise im Quellenapparat der kritischen Edition der Expositio. Die Reihe der herangezogenen Werke Alberts ist vermutlich länger als die oben erwähnten Werktitel und der Umfang der verarbeiteten, vielfach durch Ulrich von Straßburg vermittelten Texte größer als er in der kritischen Edition ausgewiesen werden konnte. ${ }^{81}$ Bezüglich der Typologie des «göttlichen Intellekts» und ihrer Erläuterung finden sich in Alberts Kommentierung der ps.-dionysischen Schrift De caelesti hierarchia, im Metaphysikkommentar und in der Summa theologiae Interpretationen, die mit denen Bertholds punktuell oder weitgehend, wenn nicht gänzlich übereinstimmen. Sie betreffen sowohl die Dreiteilung des Intellekts und seine Instanziierung ${ }^{82}$ als auch die universale Kausalität des göttlichen, aus sich selbst die Allheit hervorbringenden Intellekts. ${ }^{83}$ Als besonders auffällig ist eine große Ähnlichkeit zwischen Bertholds Auslegung der Dreiteilung des «göttlichen Intellekts» mitAlbertsdiesbezüglicher Auffassung hervorzuheben, die in seinem Metaphysikkommentar (Buch II, Kap. 2) vorliegt. Einen zwingenden Beweis, dass Berthold bei der Entfaltung seiner Lehrmeinung vom «göttlichen Intellekt» sich durch Werke Alberts leiten ließ oder sich ihrer als einer vermittelnden Quelle der Lehren

8o Albertus Magnus, De quattuor coaequaevis, tr. 4, q. 72, a. 1, S.735a: generatio mundi sensibilis prima mixta erat, ex coetu quoque constitit necessitatis et intelligentiae, hoc est, materiae et idearum, quae fuerunt in intelligentia prima: et constitit postea formata dominante intellectu divino super materiam, et trahente ipsam materiam rigidam, hoc est, nulliformae inclinatam, ad optimos actus uniuscujusque formae substantialis. Cf. Plato, Timaeus, transl. Calcidius, hg.v. J.H. Waszink (London / Leiden: Warburg Institute and Brill, 1962), 48E, S.45, L.11-13: mixta siquidem mundi sensilis ex necessitatis intelligentiaeque coetu consistit generatio dominante intellectu et salubri persuasione rigorem necessitatis assidue trahente ad optimos actus.

81 Cf. Pagnoni-Sturlese, „À propos du néoplatonisme d'Albert le Grand“, S.637ff.

82 Cf. Albertus Magnus, De quattuor coaequaevis (Summa de creaturis I), tr. 4, q. 6o, a. 2, S.635a, S.637b; Albertus Magnus, Super Dionysium De caelesti hierarchia, hg.v. P. Simon, W. Kübel (Münster i.W.: Aschendorff, 1993), c. 11, S.174, L.38ff., L.82ff.; Metaphysica, lib. 2, c. 2, S.93, L.62ff.: Triplex est autem Intellectus [...].

83 Albertus Magnus, Metaphysica, lib. 1, tr. 2, c. 4, S.22, L.2-4; Summa theologiae, lib. 1, tr. 3, q. 13, c. 1, S.39, L.79-8o. 
des Ps.-Dionysius und des Aristoteles, des Avicenna und des Averroes bedient hat, liefert diese Auffälligkeit zwar nicht. Die hier angedeuteten und die im Quellenapparat der Expositio nachgewiesenen doktrinellen und strukturellen Übereinstimmungen zwischen den beiden Autoren sowie die gemeinsamen Quellen legen dennoch eine tiefgreifende hermeneutische Koinzidenz nahe, welche in der neuplatonischen, onto-theologischen Reflexionsstruktur besteht. Sie ist für die beiden Autoren wie auch für Ulrich von Straßburg, Dietrich von Freiberg, Meister Eckhart, bis zu Heimericus de Campo der Schlüssel und das Ordnungsprinzip von Denken, Verstehen und Erklären der Seinswirklichkeit ausgehend vom "Erst-göttlichen Intellekt" als ihrem transzendenten Grund. ${ }^{84}$ Diese onto-theologische Struktur, die auf Proclus und Pseudo-Dionysius als ihr Vermittler an das Christentum und zugleich Garant ihrer Vereinbarkeit mit der Orthodoxie zurückgeht, öffnet Berthold wie Albert den Zugriff auf philosophische Traditionen, um mit deren heuristischem Instrumentarium die Wirklichkeit im Ganzen, soweit dies nur dem menschlichen Verstand möglich, zu erschließen.

ii. Weiterführende Einsichten in Bezug auf Bertholds doktrinelle Gemeinsamkeiten mit Albert und seine unmittelbaren Einflüsse auf die Expositio liefert der Kommentar zur Proposition 163. Das Proklische Theorem „Jede Viellheit von Einheiten, an welcher der Intellekt teilhat, der keine Teilhabe zulässt, ist eine intellektuale [Viellheit] "85 veranlasst Berthold in einem ersten Schritt die Eigenschaften des Intellekts zu bestimmen, der keine Teilhabe zulässt. Im nächsten Schritt erläutert er zwei Typen einer intellektualen Teilhabe, eine tätige (participatio activa) und eine erleidende (participatio passiva), und geht in einem dritten Schritt der Aussageabsicht des Proklischen Theorems nach. Er unterscheidet und instanziiert das, was nicht-teilhaftig ist, bestimmt die Arten der Teilhabe, ihre Modi und ihren Gegenstand. ${ }^{86}$ Es genügt unter dem Blickwinkel der Intellektlehre an dieser Stelle festzuhalten, dass Berthold in diesem Kontext das Erst-Eine und das Erst-Gute (prime unum et bonum) ausdrücklich als schlechthin nicht-teilhaftig (simpliciter imparticipabile) bestimmt. Hierzu zählt offenbar auch der Erst-Intellekt, sofern er als Erst- und Ursprünglich-Seiendes aus sich selbst im absoluten Sinne begriffen wird. Den Erst-Intellekt kennzeichnet er indessen wie jedes Erst- und

84 Cf. oben Anm. 39; ferner H. Anzulewicz, „Zum Einfluss des Albertus Magnus auf Heymericus de Campo im Compendium divinorum", in K. Reinhardt, H. Schwaetzer, F.-B. Stammkötter (Hgg.), Heymericus de Campo: Philosophie und Theologie im 15. Jahrhundert (Regensburg: S. Roderer-Verlag, 2009), S.83-112.

85 Berthold von Moosburg, Expositio, 163, S.24, L.2-4: Omnis multitudo unitatum, quae participatur ab imparticipabili intellectu, intellectualis est.

86 Hierzu und zum Folgenden: Berthold von Moosburg, Expositio, 163A, S.24, L.12-19. 
Primär-Seiende einer Reihe von Seienden als nicht-teilhaftig unter gewisser Rücksicht (imparticipabile in determinata intentione). In diesem Sinne ist jeder Intellekt einer intellektualen Ordnung, der an sich vollkommen konstituiert ist, nicht-teilhaftig, resümiert Berthold. ${ }^{87}$ Nicht-teilhaftig ist demnach alles, was getrennt und unvermischt ist, was keine Gemeinsamkeit und kein wesenhaftes Verhältnis zu einem anderen vorweist, mit dem es zwar wesenhaft vereint ist, aber dennoch als von diesem in jeder Beziehung wesenhaft getrennt besteht. Mit dieser Darstellung zielt Berthold unmissverständlich auf die Auffassung der anima rationalis des Aristoteles (De anima III, 4-5) ab, genauer auf den menschlichen Intellekt. Da die an Aristoteles' Schrift De anima angelehnten Versatzstücke seiner Theorie sich wörtlich in Alberts De anima-Kommentar, andere bei Dietrich von Freiberg de De animatione caeli finden und er keine Auskünfte hinsichtlich der Quellen macht, gilt es für Dietrich als bewiesen und für Albert als plausibel, dass ihre Schriften als eine unmittelbare Quelle bzw. als eine Brücke zu der littera des Aristoteles bei der Abfassung der Expositio fungiert haben. 88

Auf die inhaltliche und formale Erschließung der Proposition 163 lässt Berthold in gewohnter Manier sein eigenes Lehrstück, sog. Propositum, folgen. Den Ausgangpunkt und inhaltlichen Kern bildet der Begriff der Intellektualität sowohl als Adjektivattribut (intellectualis), das Proklos zur Bestimmung einer Vielheit von Einheiten verwendete, welche am Intellekt teilhat, der selbst nicht-teilhaftig ist, als auch als Nomen (intellectuale). Wie Pseudo-Dionysius und Albert der Große verknüpft Berthold das Verständnis dieses Begriffs mit dem Begriff der Intelligibilität und der Klärung der Differenz zwischen den beiden Begriffen. Gemeinsam für sie ist, wie er darlegt, die Erkenntnisfähigkeit (aptitudo ad intelligendum) desjenigen, dem sie zukommen. Auf Seiten des «Intellektualen» sei sie eine aktive Fähigkeit, wem auch immer sie formal oder wesenhaft oder ursächlich oder in herausragender Weise zukommt. Auf Seiten des «Intelligiblen», das seinem Sinngehalt nach abstrakter und herausragender als das Intellektuale begriffen wird, sei sie eine passive oder eine zuhöchst aktive Fähigkeit, entsprechend der Art und Weise seiner Konstituierung als Gegenstand des Intellekts. Ersteres ist gegeben, sofern das Intelligible unter Teilhabe an der Spezies eines anderen zum Gegenstand des Intellekts wird;

87 Berthold von Moosburg, Expositio, 163A, S.24, L.19-22, S.25, L.39-40: Et sic acceptum imparticipabile subdistinguitur in simpliciter imparticipabile, quod est prime unum et bonum, et imparticipabile in determinata intentione. Et sic omne prime et principaliter ens in quacumque seyra dicitur et est imparticipabile ut prime intellectus etc. [...] Et sic omnis intellectus intra ordinem intellectualem per se perfectum constitutus dicitur et est imparticipabilis. (Arist.). 
Letzteres indessen, wenn das Intelligible teilhaftig des Intellektualen ist (diesen Satzteil gibt Berthold mit participatur ad esse intelligibile wieder und verändert dadurch den Sinngehalt seiner Vorlage, die diese Stelle, wie die nachfolgende Gegenüberstellung der Texte zeigt, mit participatum ad esse intellectuale überliefert). ${ }^{89}$

In diesem Lehrstück kommen wie in einem Brennglas Informationen zusammen, welche die Frage nach Bertholds Einbettung in die Tradition Alberts des Großen in einem wichtigen Punkt der Intellektlehre beantworten und die Kontinuitätsthese in Bezug auf diese Tradition nachdrücklich bestätigen. Das Lehrstück erlaubt die verborgene Originalität einer subtilen Distinktion aufzudecken, die Berthold sich ohne ihre tatsächliche Herkunft preiszugeben zu eigen machte, indem er sie in ihrer Detailliertheit und Ausführlichkeit wortwörtlich, sieht man von einigen geringen Abweichungen ab, aus Alberts Kommentar zu De divinis nominibus (c. 4) in sein Werk aufnahm. ${ }^{90}$ Zur Verdeutlichung der Qualität, des Ausmaßes und der Art und Weise der Verarbeitung dieser Anleihe, die Berthold bei der Auslegung der Proposition 163 zur Erläuterung zweier Schlüsselbegriffe der Epistemologie und Intellektlehre aus dem Werk Alberts des Großen stillschweigend machte, seien nachfolgend der Quellentext in seiner Ursprungsform, wie er in der kritischen Edition von P. Simon vorliegt, und derselbe Text in der von Berthold in seiner Expositio überlieferten Gestalt gegenübergestellt:

\section{Albertus Magnus, Super Dionysium Berthold von Moosburg, Expositio De div. nominibus, c. 4, hg.v. Simon, super Elem. theol., 163D, hg.v. Jeck, S.121, L.20-56 Tautz, S.27, L.106-130}

Dicendum, quod sicut duplex est visibile, quoddam quod est obiectum visus sub ${ }^{\mathrm{a}}$ specie aliena, qua informatur ad esse visibile, sicut $^{\mathbf{b}}$ color, qui non potest esse obiectum visus, nisi perficiatur per lucem in esse spirituali et efficiatur

a sub Alb. non sine Berth.

b visibile, sicut $A l b$. et tale visibile est Berth. sciendum, quod, sicut est duplex visibile, quoddam, quod est obiectum visus non sine specie aliena, qua informatur ad esse, et tale visibile est color, qui non potest esse obiectum visus, nisi perficiatur per lucem in esse spirituali et efficiatur visibile

89 Berthold von Moosburg, Expositio, 163C-D, S.26, L.88-S.28, L.134.

90 Berthold von Moosburg, Expositio, 163D, S.26, L.91-92, S.27, L.104-13o. Cf. Albertus Magnus, Super Dionysium De divinis nominibus, c. 4, S.12o, L.2-3, S.121, L.2O-56. 
(cont.)

\begin{abstract}
Albertus Magnus, Super Dionysium Berthold von Moosburg, Expositio De div. nominibus, c. 4, hg.v. Simon, super Elem. theol., 163D, hg.v. Jeck, S.121, L.2O-56

Tautz, S.27, L.106-13o
\end{abstract}

visibile actu, est etiam quoddam visibile quod participatur ad naturam visibilitatis, sicut lux, si poneremus, quod non posset per se videri, ${ }^{\mathrm{c}}$ sed videretur tantum, secundum quod est participata in hoc colore vel illo ${ }^{d}$ quibus dat esse visibilitatis, quamvis quod moveant ${ }^{\mathrm{e}}$ secundum rationes determinatas, ${ }^{\mathrm{f}}$ non habeant $\mathrm{g}$ a luce, sed potius ab esse ${ }^{\mathrm{h}}$ quod habent ${ }^{i}$ in materia: ita $^{j}$ est duplex intelligibile, quoddam quod est obiectum intellectus, secundum quod participat de specie aliena, sicut species intelligibilis non est intelligibilis, nisi inquantum participat de actu intellectus agentis, qui dat sibi esse spirituale et simplex, quod possit esse perfectio intellectus possibilis. Hoc enim non habet a re, quia lapis non est in anima, sicut dicit Philosophus, sed intentio lapidis constituta in esse intelligibili per actum intellectus agentis, quamvis ab ipso non habeat, quod determinet intellectum, sed potius ab ipsa re, cuius est intentio.

c per se videri $A l b$. videri in se Berth.

d colore vel illo Alb. vel illo colore Berth.

e moveant $A l b$. moveat Berth.

f determinatas Alb. ipsum visum add. Berth.

$\mathrm{g}$ habeant $A l b$. habeat Berth.

$\mathrm{h}$ esse Alb. rei add. Berth.

i habent Alb. habet Berth.

j ita Alb. proportionaliter add. Berth. actu, est etiam quoddam visibile, quod participatur ad naturam visibilitatis, sicut lux, si poneremus, quod non posset videri in se, sed videretur tantum, secundum quod est participata in hoc vel illo colore, quibus dat esse visibilitatis, quamvis, quod moveat secundum rationes determinatas ipsum visum, non habeat a luce, sed potius ab esse rei, quod habet in materia, ita proportionaliter est duplex intelligibile: quoddam, quod est obiectum intellectus, secundum quod participat de specie aliena, sicut species intelligibilis non est intelligibilis, nisi quantum participat de actu intellectus agentis, qui dat sibi esse spirituale et simplex, quod possit esse perfectio intellectus possibilis. Hoc enim non est a re, cuius est species, quia lapis non est in anima, sed intentio lapidis constituta in esse tali intelligibili per actum intellectus agentis, quamvis ab ipso non habeat, quod determinet intellectum, sed potius a re ipsa vel phantasmate, cuius est intentio. 
(cont.)
Albertus Magnus, Super Dionysium Berthold von Moosburg, Expositio De div. nominibus, c. 4, hg.v. Simon, super Elem. theol., 163D, hg.v. Jeck, S.121, L.2O-56
Tautz, S.27, L.106-13o

Quoddam vero est intelligibile sicut participatum $^{\mathrm{k}}$ ad esse intellectuale, ${ }^{1}$ sicut lumen intellectus agentis participatur in specie intelligibili et esse etiam intellectuale. $^{\mathrm{m}}$

Dicimus ergo, ${ }^{\mathrm{n}}$ quod intelligibile primo modo dictum dicit aptitudinem passivam, sed secundo modo dictum dicit maxime activam, et $^{\mathbf{}}$ hoc convenit semper superiori naturae respectu inferioris, quia lumen superioris simplicius est et formale respectu inferioris et movens illud, lumen vero inferioris est motum a lumine superioris et possibile etp oboediens sibi. Et secundum hoc lumen superioris intelligentiae ${ }^{\mathrm{q}}$ moventis secundum philosophos recipitur ${ }^{r}$ in inferiori per omnes ordines decem, quos ponunt, ${ }^{\mathrm{s}}$ perficiens ipsum in esse intellectualitatis.
Quoddam vero intelligibile sic participatur ad esse intelligibile, sicut lumen intellectus agentis participatur in specie intelligibili, et est etiam esse intelligibile.

Dico igitur, quod intelligibile primo modo dictum dicit aptitudinem passivam, sed secundo modo dictum dicit maxime activam, et secundum hoc semper convenit naturae superiori respectu inferioris, quia lumen superioris simplex est et formale respectu inferioris et movens illud, lumen vero inferioris est motum a lumine superioris et oboediens sibi. Et secundum hoc lumen potentiae superioris moventis radicatur in inferiori perficiens ipsum in esse intellectualitatis.

\footnotetext{
k sicut participatum Alb. sic participatur Berth.

1 intellectuale $A l b$. intelligibile Berth.

m intellectuale $A l b$. intelligibile Berth.

n Dicimus ergo Alb. Dico igitur Berth.

o et Alb. secundum add. Berth.

p possibile et Alb. om. Berth.

q superioris intelligentiae Alb. potentiae superioris Berth.

r secundum philosophos recipitur Alb. radicatur Berth.

s per - ponunt Alb. om. Berth.
} 


\begin{abstract}
Alb., Super Dionysium De div. nomi- Berth., Expositio super Elem. theol., nibus, c. 4, S.119, L.76-S.12o, L.1.9-11; 163D, hg.v. Jeck, Tautz, S.28, L.131-134
\end{abstract} S.122, L.8-1O

dicit (Dionysius) superiores

substantias esse intelligibiles et intellectuales [...]. Item, dubitatur de differentia, quam ponit Commentator inter ista; dicit enim sic: Superiores dicit intelligibiles [...]. Et ideo dicuntur superiores intelligibiles, et inferiores intellectuales, quasi constituti in intellectualitate per lumen superiorum.
Et secundum hoc etiam distinguit Dionysius 4 cap. De divinis nominibus intelligibiles substantias ab intellectualibus intendens secundum Commentatorem, quod superiores sunt intelligibiles et inferiores intellectuales quasi constituti in intellectualitate per lumen superiorum.

Das aus Alberts Werk übernommene Material ergänzt Berthold mit einer Bemerkung über die natürliche Vorsehung und den genetischen Zusammenhang der Intention mit der Intellektualität und deren graduellen, dreistufigen Differenzierung. Diese umfasst intellektuale Hypostasen, die sich selbst gänzlich, wesenhaft und aktual erkennen und als Intelligenzen (intelligentiae) bezeichnet werden, ferner die göttlichen Seelen (animae totales et divinae) und Engel (angeli) einschließlich der Seelen, denen ein zweifaches Prinzip der Intellektualität, «der tätige Intellekt» als die Mitursache des ganzen niederen Seelenteils und der «mögliche Intellekt» als der innere Grund einer natürlichen Erkenntnis, eignet, weshalb sie als animae partiales bezeichnet werden. Die nachfolgende Erklärung der Intellektualität der letzten Hierarchiestufe, der Engel und der «partialen Seelen», übernimmt Berthold wortwörtlich aus Alberts Kommentar $\mathrm{zu}$ De divinis nominibus. ${ }^{91}$ Dass außer dem Begriffsverständnis von Intellektualität und Intelligibilität auch die Instanziierung dieser Begriffe eine - sieht man von geringfügigen Umformulierungen am Anfang und punktuellen Abänderungen resp. einzelnen Varianten - buchstäbliche stillschweigende Übernahme der Lehraussage Alberts darstellt, und dass sie den Kerngehalt seines gesamten Propositums bei der Auslegung der 163. Proposition der Proklischen Elementatio bildet, zeigt die nachfolgende Gegenüberstellung der entsprechenden Texte:

91 Berthold von Moosburg, Expositio, 163E, S.29, L.157-170. Albertus Magnus, Super Dionysium De divinis nominibus, c. 4, S.122, L.40-63. 


\section{Albertus Magnus, Super Dionysium Berthold von Moosburg, Expositio De divinis nominibus, c. 4, S.122, L.4O-63 super Elem. theol., 163E, hg.v. Jeck, Tautz, S.28, L.153-S.29, L.17O}

dicendum, quod eadem differentia non potest esse diversorum secundum speciem univoce reperta in eis; potest tamen utriusque esse differentia, si sit in eis secundum prius et posterius. Hoc enim verum est in omnibus totis potestativis, quod superius est aliquo modo in inferiori secundum modum possibilem sibi et per posterius; et secundum hoc intellectualitas per prius est in angelis, quorum natura accipit simplices quiditates rerum, in nobis vero est per posterius, obumbrata ${ }^{\text {a }}$ per continuum et tempus ${ }^{\mathrm{b}}$ propter hoc quod accipit a sensu et phantasmate. Et secundum ${ }^{c}$ hoc dicit Isaac, quod ratio oriturd in umbra intelligentiae; ex hoc enim quod non accipit simplicem quiditatem rei per propria principia, sed per quaedam consequentia, sicut per accidentalia $^{\mathrm{e}}$ et effectus, oportet, quod deveniat in cognitionem ${ }^{\mathrm{f}}$ disquirendo ${ }^{g}$ et comparando unum ad alterum, et accidit in ea dubitatio, quae non est in intelligentia, quae ${ }^{\mathrm{h}}$
In omnibus etiam enumeratis

intellectualibus intellectualitas est per

prius et per posterius.

Primo enim invenitur in intellectualibus hypostasibus, quibus primo et per se competit, deinde in illis, quibus competit per se, sed non primo, post quae in illis, quibus competit nec per se nec primo, inter quae tamen prius est in angelis, quorum natura accipit simplices quiditates rerum, in nobis vero est per posterius, obumbratum per continuum et tempus, et propter hoc quod accipit a sensu et phantasmate. Et propter hoc dicit Isaac, quod ratio creata est in umbra intelligentiae; ex hoc enim, quod non accipit simplicem quiditatem rei per propria principia, sed per quaedam consequentia principia, accidentia et effectus, oportet, quod deveniat in cognitionem rerum discurrendo et comparando unum ad alterum, et accidit in ea dubitatio, quod non est in angelo,

\footnotetext{
a obumbrata Alb. obumbratum Berth.

b tempus Alb. et add. Berth.

c secundum Alb. propter Berth.

d oritur Alb. creata est Berth.

e sicut per accidentalia $A l b$. principia, accidentia Berth.

f cognitionem Alb. rerum add. Berth.

g disquirendo Alb. discurrendo Berth.

h quae ... intelligentia, quae $A l b$. quod ... angelo, qui Berth.
} 
(cont.)

\section{Albertus Magnus, Super Dionysium Berthold von Moosburg, Expositio De divinis nominibus, c. 4, S.122, super Elem. theol., $163 \mathrm{E}$, hg.v. Jeck, L.4O-63 Tautz, S.28, L.153-S.29, L.17O}

simplici actione accipit quiditatem rei. Unde etiam dicit

Commentator ${ }^{\mathrm{i}}$ super VI

Ethicorum: Cave, ne animam aliquando simpliciter dicas intellectualem; sic enim non differret ab intelligentiis; sed dic eam rationalem, intellectualem vero per accidens; et hoc est: inquantum participat de luce naturae superioris. qui simplici actione, ut dictum est, accipit quiditatem rei. Unde etiam Eustratius super vi Ethicorum dicit: Cave ne animam aliquando simpliciter dicas intellectualem; sic enim non differret ab intelligentiis; sed dic eam rationabilem, intellectualem vero per accidens, hoc est: inquantum participat de luce naturae superioris.

\section{i Commentator Alb. Eustratius Berth.}

Aus Bertholds wortwörtlichen Anleihen bei Albert, die aber als solche nicht gekennzeichnet werden, ist zu schließen, dass der Exeget des Proclus sich deren Lehrgehalt uneingeschränkt zu eigen macht und ihn als seine eigene Auffassung präsentiert. Diese Intention wird man Berthold auch bei weniger durch Worttreue auffallenden Anlehnungen an Alberts Intellektlere bei der Auslegung der Propositionen 167 und 174 der Elementatio theologica unterstellen dürfen. Die Kommentare zu den beiden Theoremen spiegeln seine in Entwicklung und Differenzierung begriffene Klassifikation der Intellekte wider, für die sich ihm bei Albert eine inhaltlich breitere Grundlage als bei Dietrich von Freiberg bot. Die systematisierenden Ansätze von Bertholds Intellektlehre sollen hier nur in groben Strichen umrissen und in ihrem Verhältnis zu Albert beleuchtet werden. Auf die Berücksichtigung seiner diesbezüglichen, an Dietrich von Freiberg, Aristoteles und Averroes angelehnten Erläuterungen muss verzichtet werden, da dies den Rahmen dieses Beitrags sprengen würde.

iii. Nach der Unterscheidung und Erläuterung der göttlichen Intellekte im Kommentar zur Proposition 16o und nach einer Differenzierung der Intellekte, die keine Teilhabe zulassen, im Kommentar zur Proposition 163 sowie nach der Erörterung der für alle Intellekte gemeinsamen Eigenschaften im Kommentar zur Proposition 166 unternimmt Berthold im Kommentar zur 
Proposition $167^{92}$ eine weitere, soweit wir sehen seine vorletzte Gliederung, Systematisierung und Charakterisierung der Intellekte. Ihren Ausgangspunkt, ihre Grundlage und Richtschnur bilden nicht nur die Inhalte dieser Proposition und des sie begleitenden commentum des Proclus, sondern auch und vor allem der weitere Kontext der Expositio und die Traditionen, in denen das Werk eingebettet ist. Der philosophiehistorisch und systematisch offene Horizont der Exegese und ihr Anschluss an die Philosophy of Mind seiner Protagonisten, Dietrich von Freiberg und Albert der Großen, wird zum theoriebildenden Faktor des Bertholdschen Denksystems. Der erste, „suppositionale“ Teil seiner Auslegung der Proposition 167, der eine Klassifikation der Intellekte, die Erläuterung der einzelnen Typen und ihrer jeweils unterschiedlichen Bestimmung beinhaltet, ist derart mit Versatzstücken aus der Intellektlehre Dietrichs durchsetzt, dass er stellenweise einer literarischen Collage aus dessen Schrift De intellectu et intelligibili nahekommt. In Anlehnung an diese Schrift entwickelt Berthold eine generische, die bisherige Unterscheidung des göttlichen Intellekts erweiternde oder vielmehr nuancierende Typologie der Intellekte. Ohne eine ausdrückliche Bezugnahme auf die vorausliegende Typologie des göttlichen Intellekts - die Verknüpfung ist durch Analogie in struktureller und inhaltlicher Hinsicht offenkundig - geht er von der Unterscheidung eines schlechthin getrennten Intellekts (intellectus separatus simpliciter) und eines im uneigentlichen Sinne getrennten, gleichsam verbundenen und mit-geteilten Intellekts (intellectus non proprie separatus, sed quasi coniunctus scilicet participatus) aus. Die weitere Differenzierung und Bestimmung dieser beiden Intellekte soll im Folgenden kurz vorgestellt werden, um sie anschließend in ihrer Beziehung zur Intellektlehre Alberts zu beleuchten.

Beim schlechthin getrennten Intellekt unterscheidet Berthold zwischen dem Intellekt gemäß der Ursache in ihrer Ursprungsform (secundum causam principaliformiter) und dem Intellekt gemäß der Existenz in ihrer Wesensform (secundum existentiam essentialiter). Während der Erstere als ein einziger (unus tantum) und schlechthin getrennter Intellekt charakterisiert wird,

92 Berthold von Moosburg, Expositio, 167, S.58, L.2-8: Omnis intellectus se ipsum intelligit, sed primus quidem se ipsum solum, et unum secundum numerum in hoc intellectus et intelligibile. Unusquisque autem consequentium se ipsum simul et quae ante ipsum, et intelligibile est huic hoc quidem quod est, hoc autem a quo est. [,Jeder Intellekt erkennt sich selbst, der erste aber nur sich selbst, und der Intellekt und das Intelligible (sind) darin numerisch Eines. Jeder einzelne der nachfolgenden Intellekte indessen (erkennt) sich selbst und zugleich das, was vor ihm ist, und das Intelligible ist für ihn das 'was es ist', dies aber 'von was es ist"']; S.75, L.518-533: Commentum. 
wird der Letztere als ein durch intellektuale Hypostasen vervielfältigter begriffen. Den schlechthin getrennten Intellekt gemäß der Ursache in ihrer Ursprungsform bezeichnet Berthold in Analogie zur Bestimmung des «göttlichen Erst-Intellekts» als die sprudelnde Quelle aller Intellektualität (fontana scaturrigo omnis intellectualitatis), die ursprüngliche und wesentliche Einheit und die «Erst-Intellektualität», welche keine Teilhabe zulässt, ein in ausgezeichneter Weise Erstes und ursprungsloses Prinzip. Der getrennte Intellekt gemäß der Existenz in ihrer Wesensform hingegen ist nach seiner Auffassung absolut frei von jeder Abhängigkeit, einfach und nicht zusammensetzbar, Akt durch sich selbst. ${ }^{93}$

Beim uneigentlich getrennten Intellekt, der mit-geteilt wird, unterscheidet Berthold wie die Peripatetiker einen tätigen Intellekt (intellectus agens) und einen möglichen Intellekt. Der tätige Intellekt ist und heißt seiner Interpretation zufolge insofern verbunden (coniunctus) bzw. mit-geteilt (participatus), als er jeweils einem Individuum, sei es Engel sei es Mensch, eignet und dadurch numerisch vervielfältigt wird. Diesen Intellekt fasst er als das intrinsische und eigentliche Prinzip auf, welches Erkennen, Leben und Sein, im (neu-)platonischen Sinne die Gutheiten der Erstursache, zum individuellen Prinzip des Lebens als Erkennen eint, zum Prinzip, in dem Erkennen, Leben und Sein Eines sind. Dieser Intellekt besteht durch seine Wesenheit, da er aber ein intrinsisch-kausales Prinzip des mit ihm verbundenen Teils der Substanz ist, die er selbst ist, ist er in gewisser Weise abhängig, zusammensetzbar und nicht einfach; in seiner Substanz ist er die Tätigkeit. ${ }^{94}$

93 Berthold von Moosburg, Expositio, 167, S.58, L.18-21, S.59, L.40-46: Et iste est duplex, scilicet secundum causam principaliformiter et secundum existentiam essentialiter. Primus est unus tantum, et est simpliciter separatus, secundus autem multiplicatur intra ordinem intellectualem. [...] Verum primus intellectus, scilicet secundum causam, principaliformiter est fontana scaturrigo omnis intellectualitatis, qui, licet primo et per se sit unitas, tamen est prime intellectualitas et simpliciter imparticipabilis et amethectus et per consequens, inquantum huiusmodi, principium et ingenitum per 99. Secundus autem est essentialiter intellectus stans per essentiam suam ab omni dependentia, ut dictum est, absolutus et sic simplex et incomponibilis se ipso actus. Cf. Iremadze, Konzeptionen des Denkens im Neuplatonismus, S.156-157.

94 Berthold von Moosburg, Expositio, 167, S.58, L.22-S.59, L.35.47-50: Alius autem est intellectus non proprie separatus, sed quasi coniunctus, scilicet participatus. Et iste est duplex, scilicet agens et possibilis. Quorum primus, puta intellectus agens, est singulis singulorum et unus uniuscuiusque secundum singulos angelos et homines multiplicatus et numeratus. Supponimus enim intelligere esse vivere, sicut et vivere est esse, cum omnia sint in omnibus per 103. Vivum autem a non vivo differt in habendo in se principium sui motus. Istius autem vitae principium est intellectus agens, in quo est omnia facere secundum Aristotelem III De anima. Igitur intellectus agens est principium intrinsecum et proprium talis vitae. Non autem esset intrinsecum principium motus vitalis et per consequens nec proprium, si 
Der «mögliche Intellekt» hingegen ist „alles Seiende in Möglichkeit“ (omne ens in potentia), wie ihn Aristoteles in De anima III 5 mit der Formel „in ihm ist möglich, alles zu werden" (possibile est in eo omnia fieri) definiert hat. Da er bei jedem Individuum, dessen Intellekt er ist, den vermögenspsychologischen Grund der Erkenntnis bildet, kann er seiner Verfasstheit nach als «möglicher» weder aus sich selbst bestehen noch ist er ein ursächliches Prinzip, sondern er ist abhängig von der Substanz, die er mit dem intellectus agens teilt und wird durch die intelligiblen Spezies in den Akt überführt. ${ }^{95}$ Diese Typologie der getrennten Intellekte und die Kernpunkte ihrer Bestimmungen können überblicksweise wie folgt dargestellt werden:

1. intellectus separatus simpliciter

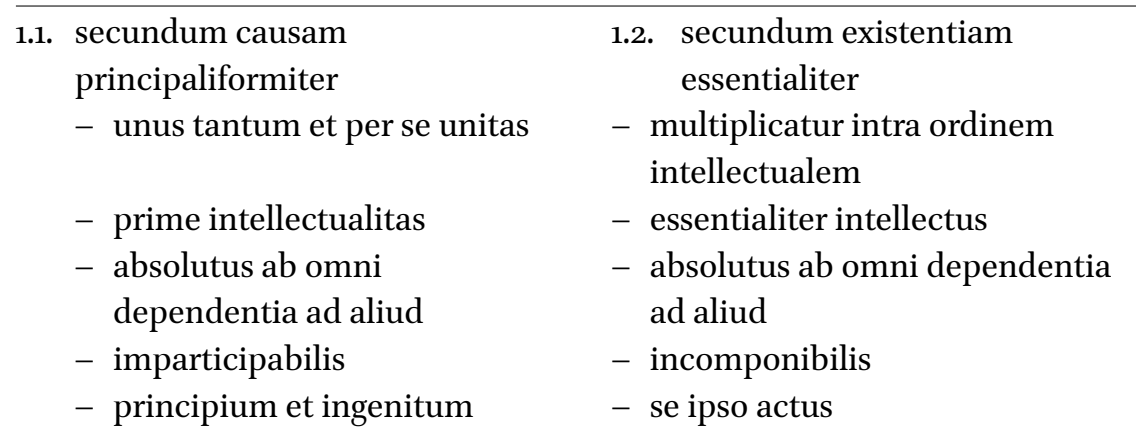

esset communis pluribus individuis, quia non esset intrinsecum secundum substantiam, sed solum secundum efectum, quod non sufficit ad hoc, quod aliquid dicatur et sit principium vitae [...] Tertius vero »intellectus, scilicet agens, et stat aliqualiter per essentiam suam, et nihilominus, cum sit principium intrinsecum causale residuae portionis substantiae, cuius est, est aliquo modo dependens. Et sic recedit a simplicitate, cum sit componibilis, et est cum hoc in sua substantia actio«. Bertholds Auffassung der Eigenschaften des tätigen Intellekts rekonstruiert Iremadze, „Der intellekttheoretische Ansatz der Selbstreflexivität des Denkens", S.246-250; dasselbe auch in: Iremadze, Konzeptionen des Denkens im Neuplatonismus, S.143-146, und vertiefend S.147-159.

95 Berthold von Moosburg, Expositio, 167A-B, S.59, L.36-38.51-54: Secundus etiam, puta intellectus possibilis, est universaliter omne ens in potentia, quod solum verum est quantum ad hoc, quod secundum Aristotelem III De anima possibile est in eo omnia fieri. [...] Quartus et ultimus intellectus, scilicet possibilis, cum sit ratio intelligendi coniuncto, in quo est, nec stat se ipso sicut agens nec est principium intrinsecum causale, cum sit possibilis, sed est dependens et speciebus intelligibilibus actuatur. Bertholds Verständnis des intellectus possibilis, seiner Wirksamkei und sachlichen sowie nominellen Formhaftikeit ist auch von Albert beeinflusst, cf. Iremadze, „Der intellekttheoretische Ansatz der Selbstreflexivität des Denkens", S.241-245, und erneut Iremadze, Konzeptionen des Denkens im Neuplatonismus, S.140-142. 
2. intellectus non-proprie separatus

2.1. intellectus agens

- in quo est omnia facere

- participatus (quasi coniunctus)

- principium intrinsecum causale residuae portionis substantiae

- stans aliqualiter in essentia sua

- aliquo modo dependens
2.2. intellectus possibilis

- in quo possibile est omnia fieri

- participatus (quasi coniunctus)

- ratio intelligendi coniuncto, in quo est

- actuatur speciebus intelligibilibus

- dependens

Was verbindet diese Typologie der Intellekte aus dem Kommentar Berthold von Moosburgs zur Proposition 167 der Elementatio theologica des Proclus mit Albertus Magnus? Ihre Grundstruktur, Begrifflichkeit und die Bestimmung der Intellekte sind von Dietrich von Freiberg inspiriert und teilweise wörtlich von ihm übernommen. Bertholds Verständnis des «tätigen» und des «möglichen Intellekts», entspricht zwar weitgehend der Auffassung Alberts, aber diese Übereinstimmung erklärt sich durch die gemeinsame für Berthold, Dietrich und Albert aristotelische Quellengrundlage. Andererseits ist nicht zu bezweifeln, dass Berthold sie auch durch die Brille Alberts liest. Eine Bestätigung dafür sind die signifikanten Übereinstimmungen mit seinen Lehransichten und wörtliche Anleihen aus seinem Werk im sogenannten propositum-Teil der Expositio Bertholds zur Proposition 167 bei der Charakterisierung des Intellekts im Akt. Seine Begründung der Immaterialität und der Getrenntheit des Intellekts entnimmt er dem Kommentar Alberts zum Buch Lambda der Metaphysik des Aristoteles; seine Quelle gibt er auch diesmal nicht preis. Wie getreu er seine Vorlage kopiert und sie nur um ein Geringes kürzt, zeigt die nachfolgende Gegenüberstellung der korrespondierenden Texte:

\section{Albertus Magnus, Metaphysica, lib. 11 Berthold von Moosburg, tr. 2 c. 31, S.523, L.19-44 Expositio, 167D, S.61, L.108-115, S.62, L.119-123}

De primo igitur, qualis sit intellectus substantiarum divinarum, determinando dicimus, quod intellectus nomine suo sonat substantiam separatam et immaterialem, quae nulli aliquid habet commune. Quidquid enim est illud quod formis,

Ex his apparet, quod intellectus nomine suo sonat substantiam seu essentiam immaterialem et separatam, quae nulli aliquid habet commune. Quidquid enim est illud quod formis, quae in ipso 
(cont.)

$\begin{array}{ll}\text { Albertus Magnus, Metaphysica, lib. } 11 & \text { Berthold von Moosburg, } \\ \text { tr. } 2 \text { c. 31, S.523, L.19-44 } & \text { Expositio, 167D, S.61, L.108-115, } \\ & \text { S.62, L.119-123 }\end{array}$

quae in ipso sunt vel ab ipso, ad nullum

sunt vel ab ipso, ad nullum esse esse alicuius formae distinguitur, omnino alicuius distinguitur, omnino est est separatum a materia. Talis autem est separatum a materia. Talis autem omnis intellectus, et agens et possibilis et quocumque alio nomine significetur. Si est omnis intellectus.

Si

enim formis distingueretur et enim formis distingueretur et determinaretur ad esse, oporteret, quod ipse omnia esset quae intelligeret; quod falsum est. Est autem materiae proprium, quod omni et soli convenit, formis, quas habet, ad esse determinari. Patet igitur omnem intellectum a materia esse absolutum.

Si autem alicui aliquid haberet commune, iam esset intellectivus eorum quae essent de natura illorum, sicut oculus non videt, nisi quae communicant cum natura perspicui, et auris non audit, nisi quae communicant cum aëre tremente, et oporteret, quod esset virtus harmonica et organica. Quae omnia impossibilia sunt et improbata a nobis in libro III De anima. Et quia non est virtus in corpore nec actus alicuius corporis, ideo omnia intelligit et universaliter est omnium et naturalium et mathematicorum et divinorum. Est igitur natura intellectualis talis ut dicta est. determinaretur ad esse, oporteret, quod ipse esset omnia, quae intelligeret; quod falsum est. Est autem materiae proprium, quod omni et soli convenit, formis, quas habet, ad esse determinari. Patet igitur omnem intellectum esse a materia absolutum [...] si enim alicui aliquid haberet commune, iam esset intellectivus eorum, quae essent de natura illorum, sicut oculus non videt, nisi quae communicant cum natura perspicui,

et oporteret, quod esset virtus harmonica et organica, tum etiam quia non est virtus in corpore nec alicuius corporis actus, ut superius est ostensum.

Trotz ihres begrenzten Umfangs fällt diese Anleihe bei Albert insofern ins Gewicht, als sie exemplarisch dokumentiert, dass und wie Berthold die intellektuelle Tradition Alberts des Großen fortführt, indem er aus seinem Werk 
schöpft, die Inhalte seiner stillschweigend übernommenen Ausführungen sich zu eigen macht und diese als seine eigene Auffassung bis auf geringfügige Abweichungen mit Alberts Worten wiedergibt. Das Beispiel gewährt einerseits einen tiefen Einblick in seine Arbeitsweise und den Umgang mit seinen Quellen, andererseits gibt es Auskunft über seine Kenntnisse und Wertschätzung der Werke und der philosophischen Ansichten Alberts, mit denen er sich in solchen Fällen wie diesem offensichtlich uneingeschränkt identifiziert. Doktrinelle Überschneidungen im großen Stil sind überdies auch durch die gemeinsamen Quellen erklärbar, insbesondere durch die Schriften des Aristoteles De anima und Metaphysica, aber auch durch die Vertrautheit und Benutzung der Kommentare Alberts zum corpus Aristotelicum einschließlich des Liber de causis sowie zu den Schriften des Pseudo-Dionysius.

iv. Die dritte und letzte Typologie der Intellekte, die aus dem intellekttheoretischen Teil der Expositio Bertholds gewonnen wird, bildet das heuristische Gerüst der Erschließung und Entfaltung der Annahme (suppositum) der 174. Proposition der Elementatio theologica des Proclus. Das Theorem "Jeder Intellekt setzt im Erkennen ein, was nach ihm ist, und sein Tun ist sein Erkennen und seine Erkenntnis ist sein Tun “96 interpretiert Berthold dahingehend, dass er es zur Vorlage für eine sechsfache Unterscheidung der Intellekte macht, die im Vergleich mit seinen früheren Typologien am weitesten ausdifferenziert ist. Da sie weder die Eigenschaften des Intellekts wie seine Immaterialität und Getrenntheit noch seine Hierarchisierung und Instanziierung noch ein anderes Kriterium explizit zum Ausgangspunkt nimmt oder diese als Erweisziel verfolgt, erscheint sie zunächst als eine Aneinanderreihung der unterschiedlich spezifizierten Intellekte, die nur geringe oder gar keine Gemeinsamkeiten mit den früheren Typologien aufweist. Genetisch und systematisch erscheint sie als dissoziiert und inkonsistent, als eine Zusammenstellung, die von sich aus kein klares und einendes Ordnungsprinzip zu erkennen erlaubt. Es steht dennoch außer Frage, dass diese Reihe, die folgende sechs Unterscheidungen des Intellekts umfasst, nicht willkürlich zustande kommt und dass sie durch die Integration in das System Bertholds ihren eigentlichen Sinn und ihre Funktion erhält, in dem sie zu einem vorzugsweise epistemologisch orientierten und von diesem Ansatz her aristotelisch inspirierten Interpretament des Proklischen Theorems wird: ${ }^{97}$

96 Berthold von Moosburg, Expositio, 174, S.136, L.2-3: Omnis intellectus intelligendo instituit, quae post ipsum, et factio intelligere et intelligentia facere; S.145, L.296-302 (Commentum Procli). Cf. Tautz, Erst-Eines, Intellekte, Intellektualität, S.35-40.

97 Berthold von Moosburg, Expositio, 174A, S.136, L.10-12: De primo sciendum, quod, ut sufficiat ad propositum, intellectus est multiplex: speculativus sive contemplativus, practicus sive operativus, adeptus, possibilis, formalis et universaliter agens. 


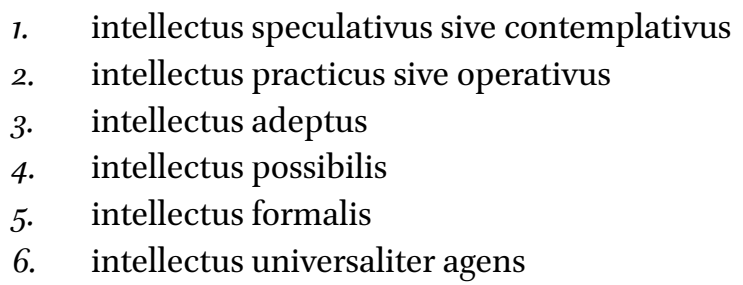

Durch diese Typologie und ihre Erklärung erschließt Berthold, wie erwähnt, die Aussageintention des Proklischen Theorems. Er führt sie auf den Kausalitätsmodus des Wissens, der jedem der angeführten Intellekte eigentümlich ist, und das Wissen oder die Wissenschaft, die durch den Intellekt generiert wird, zurück. Der Ausgangspunkt, das leitende Prinzip und das Ziel der Unterscheidung, der Anordnung und der Analyse der Intellekte ist also die Wissenschaft, deren Charakter die Intellekte bestimmen, nämlich ob sie eine allgemeine (universalis) oder partikuläre (particularis), in der Möglichkeit (in potentia) oder in Wirklichkeit (in actu) bzw. in Anwendung (in agere) ist. Dieser Typologie der Intellekte kann ein axiologischer Wesenszug insofern abgewonnen werden, als sie einem epistemologischen Finalitätsprinzip untergeordnet ist, das auf die Vollendung der Theorie selbst, nicht aber auf den Vollendungszustand der jeweiligen Stufe des Intellekts abzielt. ${ }^{98}$ Mit diesem Ansatz schließt Berthold an die aristotelische Epistemologie der Ersten Analytiken an, wobei offen bleibt, ob der Zugriff auf die Analytiken direkt oder vermittelt duch Albert den Großen erfolgt. ${ }^{99}$ Er setzt beim theoretischen bzw. betrachtenden Intellekt an, der über die Sinneswahrnehmung die Dinge betrachtend das Wissen von ihnen erzeugt. Die Charakterisierung der einzelnen, auf den theoretischen Intellekt folgenden Intellekte beschränkt er auf wenige Bemerkungen und Verweise auf seine im Kommentar zu der Proposition 171 zurückliegenden Erörterungen, die den möglichen Intellekt (intellectus possibilis) und den formalen Intellekt (intellectus formalis) betreffen. Bezüglich der Letzteren sei angemerkt, dass sie weitgehend die Auffassung

98 Bezüglich der Vollendungsstufen des Intellekts cf. Berthold von Moosburg, Expositio, 111, S.19-21.

99 Aristoteles, Analytica priora, lib. 2, c. $21\left(67 b_{3}-5\right)$; transl. Boeth.: Aristoteles Latinus, III.14, hg.v. L. Minio-Paluello (Brugge / Paris: Desclée de Brouwer, 1962), S.131, L.18-19: Nam scire dicitur tripliciter, aut in universali, aut ut propria aut ut agere. Cf. Albertus Magnus, Analytica priora, lib. 2, tr. 6, c. 9, hg.v. A. Borgnet (Paris: Vivès, 189o), S.781b. H. Anzulewicz, „Alberts Konzept der Bildung durch Wissenschaft", in L. Honnefelder (Hg.), Albertus Magnus und der Ursprung der Universitätsidee (Berlin: Berlin University Press, 2011), S.395-396, 543-544. 
des Dietrich von Freiberg, des Aristoteles und des Averroes widerspiegeln, eine Tradition, die man gelegentlich als den deutschen Sonderweg bezeichnet, der durch Albert den Großen maßgeblich vorbereitet wurde. Bertholds Bestimmungen des praktischen, des erworbenen und des allgemein tätigen Intellekts lassen sich kurz wie folgt zusammenfassen: Der praktische Intellekt empfängt keine Erkenntnisinhalte von den Dingen, sondern er prägt vielmehr, sich des Körpers bedienend, den Dingen seine Form ein; er wirkt durch sich selbst wie etwa die formende Kraft im Samen, oder akzidentell wie ein Handwerker, der gemäß einer angeeigneten Form ein Werk gestaltet, welches das Ziel des praktischen Intellekts sei. Der erworbene Intellekt (intellectus adeptus) ist indessen Intellekt im Akt, der diesen Zustand durch den tätigen Intellekt (intellectus agens) als Akt des eigenen, möglichen Intellekts erlangt hat. Der allgemein wirkende Intellekt (intellectus universaliter agens) ist, wie Aristoteles in De anima III 5 ihn beschreibt, das Prinzip, 'wodurch alles Tun ist und kein Aufnehmen'. M.R. Pagnoni-Sturlese hat minutiös aufgezeigt, dass Bertholds Darstellung des allgemein wirkenden Intellekts die von Ulrich von Straßburg vermittelte Auffassung Alberts des Großen widerspiegelt, wie diese in dessen Werk De causis et processu universitatis a prima causa, lib. I tr. 2 c. 1 vorliegt. ${ }^{100}$

Wird Bertholds Typologie der Intellekte und ihre Erklärung mit den Einteilungen der Intellekte verglichen, die Albert in seinen Schriften vom Frühwerk De homine bis zu De intellectu et intelligibili entwickelte, sind die meisten Übereinstimmungen mit seinen Einteilungen in der letztgenannten Schrift feststellbar. Sie decken sich aber weder in der Anordnung der einzelnen Glieder noch in deren Zahl. Im Unterschied zu Berthold begreift und ordnet Albert die Intellekte nicht von ihren als theoretisch bzw. praktisch aufgefassten Ziel her, d.h. dem Wissen bzw. der Wissenschaft, sondern vom Subjekt her als dessen konstitutives Formprinzip und Vermögen, dessen Vollendungsstufen die einzelnen Intellekte verkörpern. ${ }^{101}$ Die unterschiedlichen Ansätze der beiden Denker schließen dennoch nicht aus, dass Berthold sich von Alberts Auffassung inspirieren ließ und ähnlich wie Albert drei Vollendungsstufen des Intellekts annahm, wie dem kritischen Quellenapparat zum Kommentar der Proposition 174 und der Auslegung der Proposition 111 zu entnehmen ist, in der Ausgestaltung der Intellektlehre indes, deren Kernstück die Klassifikation der

\footnotetext{
100 Pagnoni-Sturlese, „À propos du néoplatonisme d'Albert le Grand“, S.638-644.

101 Cf. H. Anzulewicz, „Entwicklung und Stellung der Intellekttheorie im System des Albertus Magnus", in Archives d'Histoire Doctrinale et Littéraire du Moyen Âge 70(2003), S.165-218, esp. S.193-198.
} 
Intellekte und ihre Kriterien bilden, einen durch Dietrich von Freiberg vorbereiteten, letztlich aber doch eigenen Weg gewählt hat. ${ }^{102}$

Bestimmen die Proklische Vorlage den inhaltlichen Fluss und Dietrich von Freibergs Doktrin Bertholds Exegese, gehört Albert mit seinen Schriften, von denen De causis et processu universitatis a prima causa und die Kommentarwerke Super Dionysium De divinis nominibus, Metaphysica und Physica hervorzuheben sind, zu den wichtigen Quellen der Intellekttheorie Bertholds. Es lag offenkundig nicht nur an punktuellen Übereinstimmungen in der Intellekttheorie dieser beiden Denker, sondern an deren weit größeren doktrinalen Nähe, die sich auf dem Gebiet der theologischen Philosophie fruchtbar erwies. Diese systemische Koinzidenz zeigt sich auch am Schluss des intellekttheoretischen Teils der Expositio Bertholds Exegese der 181. Proposition "Jeder mit-geteilte Intellekt ist entweder göttlich als einer, der mit den Göttern äußerlich verbunden ist, oder allein intellektual“ ${ }^{103}$ Zur Erklärung der partizpatorisch aufgefassten Verbindung der göttlichen Intellekte mit den Göttern greift Berthold auf Alberts Interpretation der Emanationslehre aus dem ersten Buch der Schrift De causis et processu universitatis a prima causa zurück. Sie bot sich insofern als hilfreich zur Erschließung der Sinngehalte des Proklischen Theorems an, als sie die Teilhabe emanatistisch interpretiert. ${ }^{104}$ Ein derart leistungsfähiges, die Proclus-Exegese dieses Theorems wie auch der Elementato theologica insgesamt unterstützendes Rüstzeug bot seitens der lateinischen Tradition in dieser Zeit außer Dietrich und Albert kaum ein anderer bedeutender Denker, auch nicht Thomas von Aquin.

\section{Schlussbemerkungen}

Berthold von Moosburg vertritt mit seinem Kommentar zur Elementatio theologica des Proclus zwar die neuplatonische Tradition in ihrer genuinen Verankerung, aber nicht in ihrer absolut reinen Form, wie sich an seiner Intellektlehre u. a. an der drittletzten Typologie der Intellekte und durchgängig an seinen Quellen ablesen lässt. Seine Intellektlehre, ihre neuplatonischen, durch die Theoreme des Proclus fixierten und um aristotelische

\footnotetext{
102 Cf. Quellen- und Similia-Nachweise in Bertholds Expositio, 174, S.136-144. Tautz, Erst-Eines, Intellekte, Intellektualität, S.97; oben Anm. 98.

103 Berthold von Moosburg, Expositio, 181, S.221, L.2-4: Omnis participatus intellectus aut divinus est tamquam diis extra iunctus aut intellectualis solum. Cf. E. Ludueña, „El politeísmo de Proclo en la Expositio de Bertoldo de Moosburg“, in S. Filippi, M. Coria (Hgg.), La Identidad propia del Pensamiento Patrístico y Medieval: ¿Unidad y Pluralidad? (Rosario: Paideia Publicaciones, 2014), S.393-403.

104 Cf. De Libera, La Mystique rhénane, S.352ff.
} 
Grundannahmen ergänzten Positionen sowie sein Verständnis der Metaphysik des Einen und des Guten weisen ihn als einen konsequenten Vertreter der "theologischen Philosophie“ aus. Sein onto-theologisch fundiertes, in der (neu-)platonischen und biblisch-christlichen Tradition verankertes Denken lässt sich weder mit einem „absoluten philosophischen Immanentismus“ ausweisen, noch durch angebliche innere Zerrissenheit in seiner Konsistenz in Frage stellen. ${ }^{105}$ Es wäre aber auch ein reduktionistischer Fehlschluss, seine Expositio super Elementationem des Proclus nur als einen Versuch der Neukonstituierung des Verhältnisses von Platonismus und Aristotelismus unter den veränderten Einsichten bezüglich der pseudo-aristotelischen Autorschaft des Liber de causis und des vermeintlich endgültigen Scheiterns der Harmonisierung der heterogenen Traditionen auf dem Gebiet der Metaphysik resp. des paganen (Neu-)Platonismus und des Christentum zu sehen. ${ }^{106}$ Die Bertholds Denken und Werk kennzeichnende Permeabilität von Philosophie und Theologie, von (Neu-)Platonismus und Aristotelismus bricht aus dem systemisch geschlossenen und historisch gefestigten Denkraster, will man das Werk als dessen Projektionsfläche betrachten und beurteilen, statt dem Autor selbst und seiner «theologischen Philosophie» das Wort reden lassen. Albert der Große dürfte für Berthold der Prototyp seines an die littera Procli gebundenen Philosophierens sein. Obwohl ihm, dem ersten Proclus-Kommentator im lateinischen Westen kaum gelungen ist, diese neuplatonische Tradition in der Lateinischen Welt nachhaltig zu festigen, ist er mit seinem Vorhaben, die Kontinuität der Platonischen Tradition im Mittelalter und über das Mittelalter hinaus zu sichern, nicht gescheitert, denn sein Text spricht auch zu uns heute und ruft ein „Gezänk seiner Ausleger“107 hervor.

\section{Bibliographie}

\section{Handschriften}

Köln, Hist. Archiv der Stadt, Codex W 258a.

Wien, Österreichische Nationalbibliothek 273.

105 Cf. Flasch, „Einleitung“, S.XIII-XIV, XVI, XXVIII, XXX.

106 Cf. W. Goris, „Metaphysik und Einheitswissenschaft bei Berthold von Moosburg“, in Recherches de Théologie et Philosophie médiévales 85(2018), S.239-258, bes. $256-258$. E. Ludueña, „Dioses, inteligencias y ángeles de Alberto Magno a Bertoldo de Moosburg“, in Cuadernos de filosofía 66(2016), S.54-55.

107 Cf. K. Flasch, „Von Dietrich zu Albert“, in Freiburger Zeitschrift für Philosophie und Theologie 32(1985), S.7. Der Schlusssatz drückt eine Gegenteilige Auffassung zum Urteil von B. Mojsisch, dessen Ansicht nach Bertholds Projekt letztlich missglückt ist; cf. Mojsisch, „Die Theorie des Intellekts bei Berthold von Moosburg“, S.176. 


\section{Primäre Quellen}

Albertus Magnus, De vegetabilibus libri VII, hg.v. E. Meyer, K. Jessen, Berlin, Reimer, 1867 .

Albertus Magnus, Commentarii in III Sententiarum, hg.v. A. Borgnet, Paris, Vivès, 1894. Albertus Magnus, De quattuor coaequaevis (Summa de creaturis pars I), hg.v. A. Borgnet, Paris, Vivès, 1895, S.307-761.

Albertus Magnus, De resurrectione, hg.v. W. Kübel, Münster i.W., Aschendorff, 1958, S.237-354.

Albertus Magnus, Metaphysica, lib. I-v, hg.v. B. Geyer, Münster i.W., Aschendorff, 196o. Albertus Magnus, Metaphysica, lib. vI-XIII, hg.v. B. Geyer, Münster i.W., Aschendorff, 1964.

Albertus Magnus, De anima, hg.v. C. Stroick, Münster i.W., Aschendorff, 1968.

Albertus Magnus, Super Dionysium De divinis nominibus, hg.v. P. Simon, Münster i.W., Aschendorff, 1972.

Albertus Magnus, Summa theologiae sive de mirabili scientia dei, libri I pars I, quaestiones 1-5oA, hg.v. D. Siedler / W. Kübel / H.-J. Vogels, Münster i.W., Aschendorff, 1978.

Albertus Magnus, Super Ethica. Commentum et quaestiones, lib. VI-X, hg.v. W. Kübel, Münster i.W., Aschendorff, 1987.

Albertus Magnus, De causis et processu universitatis a prima causa, hg.v. W. Fauser, Münster i.W., Aschendorff, 1993.

Albertus Magnus, Super Dionysium De caelesti hierarchia, hg.v. P. Simon, W. Kübel, Münster i.W., Aschendorff, 1993.

Aristoteles, Analytica priora. Translatio Boethii, hg.v. L. Minio-Paluello, Aristoteles Latinus, III.1-4, Brugge - Paris, Desclée de Brouwer, 1962.

Aristoteles Graece. Ex recensione I. Bekkeri ed. Academia Regia Borussica, vol. I, Berlin, 1831.

Berthold von Moosburg, Expositio super Elementationem theologicam Procli. Prologus, Propositiones 1-5, hg.v. L. Sturlese; Propositiones 6-13, hg.v. M.R. Pagnoni-Sturlese, Hamburg, Meiner, 1984.

Berthold von Moosburg, Expositio super Elementationem theologicam Procli. Propositiones 35-65, hg.v. A. Sannino, mit einem Vorwort von L. Sturlese, Hamburg, Meiner, 2001.

Berthold von Moosburg, Expositio super Elementationem theologicam Procli. Propositiones 160-183, hg.v. U.R. Jeck, I.J. Tautz; Prolegomena und Indices, hg.v. N. Bray, Hamburg, Meiner, 2003.

Berthold von Moosburg, Expositio super Elementationem theologicam Procli. Propositiones 108-135, hg.v. F. Retucci, Hamburg, Meiner, 2011.

Berthold von Moosburg, Expositio super Elementationem theologicam Procli. Propositiones 184-211, hg.v. L. Sturlese, A. Punzi, Hamburg, Meiner, 2014. 
Dietrich von Freiberg, De subiecto theologiae (fragmentum), hg.v. L. Sturlese, in Dietrich von Freiberg, Schriften zur Naturphilosophie und Metaphysik, hg.v. J.-D. Cavigioli et al., Hamburg, Meiner, 1983, S.275-282.

Dionysiaca. Recueil donnant l'ensemble des traductions latines des ouvrages attribués au Denys de l'Aréopage, hg.v. Ph. Chevallier, vol. I, Brugge, Desclée de Brouwer \& Co., 1937.

Dionysius Areopagita, Ps.-, De divinis nominibus, hg.v. B.R. Suchla, Corpus Dionysiacum I. Patristische Texte und Studien, vol. 33, Berlin / New York, De Gruyter, 1990.

Dionysius Areopagita, Ps.-, siehe Dionysiaca.

Plato, Timaeus, transl. Calcidius, hg.v. J.H. Waszink, London / Leiden, Warburg Institute and Brill, 1962.

Proclus, Elementatio theologica, hg.v. H. Boese, Leuven, Leuven University Press, 1987.

Proclus, De providentia et fato et eo quod in nobis ad Theodorum Mechanicum, hg.v. H. Boese, in Procli Diadochi Tria Opuscula (De providentia, Libertate, Malo) Latine Guilelmo de Moerbeka vertente et Graece ex Isaacii Sebastocratoris aliorumque scriptis collecta, hg.v. H. Boese, Berlin, De Gruyter, 196o, S.109-171.

Ulrich von Straßburg, De summo bono. Liber 2, Tractatus 5-6, hg.v. A. Beccarisi, Hamburg, Meiner, 2007.

\section{Sekundäre Quellen}

Anzulewicz, H., Die theologische Relevanz des Bildbegriffs und des Spiegelbildmodells in den Frühwerken des Albertus Magnus, Münster, Aschendorff, 1999.

Anzulewicz, H., „Die Denkstruktur des Albertus Magnus. Ihre Dekodierung und ihre Relevanz für die Begrifflichkeit und Terminlogie“, in J. Hamesse, C. Steel (Hgg.), L'Élaboration du vocabulaire philosophiques au Moyen Âge, Turnhout, Brepols 20oo, S.369-396.

Anzulewicz, H., „Pseudo-Dionysius Areopagita und das Strukturprinzip des Denkens von Albert dem Großen“, in T. Boiadjiev, G. Kapriev, A. Speer (Hgg.), Die Dionysius-Rezeption im Mittelalter, Turnhout, Brepols, 2000, S.251-295.

Anzulewicz, H., „Entwicklung und Stellung der Intellekttheorie im System des Albertus Magnus“, in Archives d'Histoire Doctrinale et Littéraire du Moyen Âge 70(2003), S.165-218.

Anzulewicz, H., „Zum Einfluss des Albertus Magnus auf Heymericus de Campo im Compendium divinorum“, in K. Reinhardt, H. Schwaetzer, F.-B. Stammkötter (Hgg.), Heymericus de Campo: Philosophie und Theologie im 15. Jahrhundert, Regensburg, S. Roderer-Verlag, 2009, S.83-112.

Anzulewicz, H., „Solus homo est nexus Dei et mundi. Albertus Magnus über den Menschen“, in S. Fernández, J. Noemi, R. Polanco (Hgg.), Multifariam. Homenaje a los profesores A. Meis, A. Bentué, S. Silva, Santiago de Chile, Pontificia Universidad Católica de Chile, 2010, S.321-335. 
Anzulewicz, H., „Alberts Konzept der Bildung durch Wissenschaft“, in L. Honnefelder (Hg.), Albertus Magnus und der Ursprung der Universitätsidee, Berlin, Berlin University Press, 2011, S.382-397, 538-548.

Anzulewicz, H., „Albertus Magnus über die philosophi theologizantes und die natürlichen Voraussetzungen postmortaler Glückseligkeit: Versuch einer Bestandsaufnahme“, in C. Steel, J. Marenbon, W. Verbeke (Hgg.), Paganism in the Middle Ages: Threat and Fascination, Leuven, University Press, 2012, S.55-83.

Anzulewicz, H., „Hervorgang - Verwirklichung - Rückkehr. Eine neuplatonische Struktur im Denken Alberts des Großen und Dietrichs von Freiberg“, in K.-H. Kandler, B. Mojsisch, N. Pohl (Hgg.), Die Gedankenwelt Dietrichs von Freiberg im Kontext seiner Zeitgenossen, Freiberg, Technische Universität Bergakademie Freiberg, 2013, S.229-244.

Anzulewicz, H., „Scientia mystica sive theologia - Alberts des Großen Begriff der Mystik“, in Roczniki Filozoficzne 63(2015), S.37-58.

Anzulewicz, H., „De intellectu et intelligibili des Albertus Magnus: Eine Relektüre der Schrift im Licht ihrer peripatetischen Quellen“, in Przegląd Tomistyczny 25(2019), S.71-104.

Baneu, A., Calma, D., „Notes sur un commentaire inédit au Liber de causis (Augsburg, Staats- und Stadtbibliothek, $4^{\circ}$ Cod. 68)“, in Bulletin de Philosophie Médiévale 54(2012), S.277-296.

Beccarisi, A., „Einleitung“, in Ulrich von Straßburg, De summo bono. Liber 2, Tractatus 5-6, hg.v. A. Beccarisi, Hamburg, Meiner, 2007, S.vII-XX.

Beierwaltes, W., „Der Begriff des 'unum in nobis' bei Proklos“, in P. Wilpert, W.P. Eckert (Hgg.), Die Metaphysik im Mittelalter: Ihr Ursprung und ihre Bedeutung, Berlin, De Gruyter, 1963, S.255-266.

Boese, H., „Einleitung“, in Proclus, Elementatio theologica, translata a Guillelmo de Morbecca, hg.v. H. Boese, Leuven, Leuven University Press, 1987, S.IX-XXXIV.

Calma, D., „The Exegetical Tradition of Medieval Neoplatonism. Considerations on a Recently Discovered Corpus of Texts“, in D. Calma (Hg.), Neoplatonism in the Middle Ages. I. New Commentaries on Liber de causis (ca. 1250-1350), Turnhout, Brepols, 2016, S.11-52.

Calma, D., „A Medieval Companion to Aristotle: John Krosbein's Paraphrases on Liber de causis “, in D. Calma (Hg.), Neoplatonism in the Middle Ages. II. New Commentaries on Liber de causis and Elementatio theologica (ca. 1350-1500), Turnhout, Brepols, 2016, S.11-97.

Calma, D., „Reading Proclus and the Book of Causes: Notes on the Western Scholarly Networks and Debates", in Calma (Hg.), Reading Proclus and the Book of Causes. Volume 1, S.1-13.

Calma, D. (Hg.), Reading Proclus and the Book of Causes. Volume 1 Western Scholarly Networks and Debates, Leiden / Boston, Brill, 2019. 
Colli, A., "Intellectus agens als abditum mentis. Die Rezeption Augustins in der Intellekttheorie Dietrichs von Freiberg“, in Theologie und Philosophie 86(2011), S.36o-371.

Eckert, W., Berthold von Moosburg O.P. und sein Kommentar zur Elementatio theologica des Proklos, PhD Diss., Ludwig-Maximilians-Universität München, 1956.

Eckert, W., „Berthold von Moosburg O.P. Ein Vertreter der Einheitsmetaphysik im Spätmittelalter“, in Philosophisches Jahrbuch 65(1957), S.120-133.

Eckert, W., „Berthold von Moosburg O.P.“, in Die deutsche Literatur des Mittelalters: Verfasserlexikon, hg.v. K. Ruh et al., Bd. 1, Berlin / New York, De Gruyter, ${ }^{2} 1978$, col. 816-817.

Eckert, W., „Berthold von Moosburg OP“, in Lexikon des Mittelalters, vol. 1, München / Zürich, Artemis, 198o, col. 2034.

Faes de Mottoni, B., „Il commento di Bertoldo di Moosburg all' 'Elementatio theologica' di Proclo. Edizione delle proposizioni riguardanti il tempo e l'eternità“, in Studi medievali, Ser. 3, 12(1971), S.417-461.

Fauser, W., Die Werke des Albertus Magnus in ihrer handschriftlichen Überlieferung. Teil I: Die echten Werke, Münster i.W., Aschendorff, 1982.

Flasch, K., „Einleitung“, in Berthold von Moosburg, Expositio super Elementationem theologicam Procli. Prologus. Propositiones 1-13, hg.v. M.R. Pagnoni-Sturlese, L. Sturlese, Hamburg, Meiner, 1984, S.XI-XXXVIII.

Flasch, K., „Von Dietrich zu Albert“, in Freiburger Zeitschrift für Philosophie und Theologie 32(1985), S.7-26.

Flasch, K., „Procedere ut imago. Das Hervorgehen des Intellekts aus seinem göttlichen Grund bei Meister Dietrich, Meister Eckhart und Berthold von Moosburg“, in K. Ruh (Hg.), Abendländische Mystik im Mittelalter. Symposion Kloster Engelberg 1984, Stuttgart, Metzlersche Verlagsbuchhandlung, 1986, S.125-134.

Flasch, K., Sturlese, L., „Vorwort“, in Berthold von Moosburg, Expositio super Elementationem theologicam Procli. Prologus. Propositiones 1-13, hg.v. M.R. PagnoniSturlese, L. Sturlese, Hamburg, Meiner, 1984, S.IX-X.

Führer, M., Gersh, S., „Dietrich of Freiberg and Berthold of Moosburg“, in S. Gersh (Hg.), Interpreting Proclus. From Antiquity to the Renaissance, Cambridge, Cambridge University Press, 2014, S.299-317.

Gersh, S.E., „Berthold von Moosburg and the Content and Method of Platonic Philosophy“, in J.A. Aertsen, K. Emery, Jr., A. Speer (Hgg.), Nach der Verurteilung von 1277. Philosophie und Theologie an der Universität von Paris im letzten Viertel des 13. Jahrhunderts. Studien und Texte, Berlin / New York, De Gruyter, 2001, S.493-503.

Goris, W., „Metaphysik und Einheitswissenschaft bei Berthold von Moosburg“, in Recherches de Théologie et Philosophie médiévales 85(2018), S.239-258.

Grabmann, M., „Studien über Ulrich von Straßburg“, in M. Grabmann, Mittelalterliches Geistesleben. Abhandlungen zur Geschichte der Scholastik und Mystik [vol. I], München, Hueber, 1926, S.147-221. 
Grabmann, M., „Der Einfluss Alberts des Großen auf das mittelalterliche Geistesleben“, in M. Grabmann, Mittelalterliches Geistesleben. Abhandlungen zur Geschichte der Scholastik und Mystik, vol. II, München, Hueber, 1936, S.324-412.

Imbach, R., „Chronique de Philosophie: Le (néo-)platonisme médiéval, Proclus latin et l'école dominicaine allemande“, in Revue ed Théologie et de Philosophie 110(1978), S.427-448; repr.: R. Imbach, Quodlibeta. Ausgewählte Artikel / Articles choisis, hg.v. F. Cheneval et al., Freiburg, Schweiz, Universitätsverlag, 1996, S.129-151.

Imbach, R., „Au-delà de la métaphysique: Notule sur importance du Commentaire de Berthold de Moosburg OP sur les Éléments de théologie“, in D. Calma (Hg.), Reading Proclus and the Book of Causes. Volume 1, S.376-393.

Iremadze, T., „Der intellekttheoretische Ansatz der Selbstreflexivität des Denkens gemäß Kapitel 168 der Elementatio theologica des Proklos und seine Deutung sowie Entfaltung im Proklos-Kommentar Bertholds von Moosburg“, in W. Geerlings, C. Schulze (Hgg.), Der Kommentar in Antike und Mittelalter, Bd. 2: Neue Beiträge zu seiner Erforschung, Leiden / Boston, Brill, 2004, S.237-253.

Iremadze, T., Konzeptionen des Denkens im Neuplatonismus. Zur Rezeption der Proklischen Philosophie im deutschen und georgischen Mittelalter: Dietrich von Freiberg - Berthold von Moosburg - Joane Petrizi, Amsterdam / Philadelphia, Grüner, 2004 .

Jorissen, H., Anzulewicz, H., „Lumen naturale“, in W. Kasper et al. (Hgg.), Lexikon für Theologie und Kirche, vol. VI, Freiburg / Basel / Roma / Wien, Herder, 1997, col. 1120-21.

King, E., „Berthold of Moosburg on Intellect and the One of the Soul“, in Dionysius 36(2018), S.184-199.

King, E., „Eriugenism in Berthold of Moosburg's Expositio super Elementationem theologicam Procli“, in Calma (Hg.), Reading Proclus and the Book of Causes. Volume 1, S.394-437.

Klibansky, R., Ein Proklos-Fund und seine Bedeutung. Sitzungsberichte der Heidelberger Akademie der Wissenschaften, Philosophisch-historische Klasse, Jahrgang 1928/29, 5. Abhandlung, Heidelberg, Winter, 1929.

Krebs, E., Meister Dietrich (Theodoricus Teutonicus de Vriberg). Sein Leben, seine Werke, seine Wissenschaft, Münster, Aschendorff, 1906.

Lastra Sheridan, J.C., „La influencia de los principales tópicos filosóficos del Asclepius en la obra de Alberto Magno“, in V. Buffon, C. D’Amico (Hgg.), Hermes Platonicus. Hermetismo y platonismo en el Medioevo y la Modernidad temprana, Santa Fe, Universidad Nacional del Litoral, 2016, S.127-146.

Libera, A. de, La Mystique rhénane. D’Albert le Grand à Maître Eckhart, Paris, Éditions du Seuil, 1994 .

Ludueña, E., „El politeísmo de Proclo en la Expositio de Bertoldo de Moosburg“, in S. Filippi, M. Coria (Hgg.), La Identidad propia del Pensamiento Patrístico y Medieval: ¿Unidady Pluralidad?, Rosario, Paideia Publicaciones, 2014, S.393-4O3. 
Ludueña, E., „Dioses, inteligencias y ángeles de Alberto Magno a Bertoldo de Moosburg“, in Cuadernos de filosofía 66(2016), S.47-59.

Ludueña, E., „La recepción del Asclepius en Bertoldo de Moosburg“, in V. Buffon, C. D’Amico (Hgg.), Hermes Platonicus. Hermetismo y platonismo en el Medioevo y la Modernidad temprana, Santa Fe, Universidad Nacional del Litoral, 2016, S.165-181.

Massa, E., „La deificazione nel Commento di Bertoldo di Moosburg a Proclo, Elementatio theologica, 129. Edizione del testo e primi analisi“, in R. Lievens, E. Van Mingroot, W. Verbeke (Hgg.), Pascua Mediaevalia: Studies voor Prof. Dr. J.M. De Smet, Leuven, Leuven University Press, 1983, S.545-6o4.

Meyer, E., Jessen, K., „Appendices“, in Albertus Magnus, De vegetabilibus libri VII, hg.v. E. Meyer, K. Jessen, Berlin, Reimer, 1867, S.663-693.

Mojsisch, B., „»Dynamik der Vernunft« bei Dietrich von Freiberg und Meister Eckhart“, in K. Ruh (Hg.), Abendländische Mystik im Mittelalter. Symposion Kloster Engelbert 1984, Stuttgart, Metzlersche Verlagsbuchhandlung, 1986, S.135-144.

Mojsisch, B., „Die Theorie des Intellekts bei Berthold von Moosburg. Zur Proklosrezeption im Mittelalter“, in Th. Kobusch, B. Mojsisch, O.F. Summerell (Hgg.), Selbst - Singularität - Subjektivität. Vom Neuplatonismus zum deutschen Idealismus, Amsterdam / Philadelphia, Grüner, 2002, S.175-184.

Ostlender, H., „Die Autographe Alberts des Großen“, in H. Ostlender (Hg.), Studia Albertina. Festschrift für Bernhard Geyer zum 70. Geburtstage, Münster i.W., Aschendorff, 1952, S.3-21.

Pagnoni-Sturlese, R., „À propos du néoplatonisme d'Albert le Grand. Aventures et mésaventures de quelques textes d'Albert dans le Commentaire sur Proclus de Berthold de Moosburg“, in Archives de Philosophie 43(1980), S.635-654.

Porreca, D., „Albertus Magnus and Hermes Trismegistus: An Update“, in Mediaeval Studies 72(2010), S.245-281.

Retucci, F., „Sententia Procli alti philosophi. Notes on Anonymous Commentary on Proclus' Elementatio theologica“, in D. Calma (Hg.), Neoplatonism in the Middle Ages. II. New Commentaries on Liber de causis and Elementatio theologica (ca.1350-1500), Turnhout, Brepols, 2016, S.99-179.

Roesner, M., Logik des Ursprungs. Vernunft und Offenbarung bei Meister Eckhart, Freiburg / München, Alber, 2017.

Rubczyński, W., „Studia neoplatońskie“, in Przeglad Filozoficzny 3(1900), S.41-69.

Schumacher, L., Theological Philosophy. Rethinking the Rationality of Christian Faith, Farnham, Ashgate, 2015.

Shihadeh, A., Thiele, J. (Hgg.), Philosophical Theology in Islam. Later Asharism East and West, Leiden, Brill, 2020.

Siedler, D., Simon, P., „Prolegomena“, in Albertus Magnus, Summa theologiae sive de mirabili scientia dei, libri primi pars I, quaestiones 1-50A, hg.v. D. Siedler, W. Kübel, H.-J. Vogels, Münster i.W., Aschendorff, 1978, S.V-XXVI. 
Stehkämper, H., Albertus Magnus. Ausstellung zum 70o. Todestag [Katalog], Köln, Historisches Archiv der Stadt, 1980.

Struve, H., „Die polnische Philosophie der letzten zehn Jahre (1894-1904)“, in Archiv für Geschichte der Philosophie 18(1905), S.559-584.

Sturlese, L., „Introduzione“, in Bertoldo di Moosburg, Expositio super Elementationem theologicam Procli, 184-211: De animabus, hg.v. L. Sturlese, Roma, Edizioni di Storia e Letteratura, 1974, S.XIII-LXXXIII.

Sturlese, L., „Proclo ed Ermete in Germania da Alberto Magno a Bertoldo di Moosburg“, in K. Flasch (Hg.), Von Meister Dietrich zu Meister Eckhart, Hamburg, Meiner, 1984, S.22-33.

Sturlese, L., „Note su Bertoldo di Moosburg O.P., scienziato e filosofo“, in Freiburger Zeitschrift für Philosophie und Theologie 32(1985), S.249-259.

Sturlese, L., „Homo divinus. Der Prokloskommentar Bertholds von Moosburg und die Probleme der nacheckhartschen Zeit“, in K. Ruh (Hg.), Abendländische Mystik im Mittelalter. Symposion Kloster Engelbert 1984, Stuttgart, Metzlersche Verlagsbuchhandlung, 1986, S.145-161; repr.: „Der Prokloskommentar Bertholds von Moosburg und die philosophischen Probleme der nacheckhartschen Zeit“, in L. Sturlese, Homo divinus: Philosophische Projekte in Deutschland zwischen Meister Eckhart und Heinrich Seuse, Stuttgart, Kohlhammer, 2007, S.137-154.

Tautz, I.J., Erst-Eines, Intellekte, Intellektualität. Eine Studie zu Berthold von Moosburg, Hamburg, Kovač, 2002.

Zavattero, I., „La figura e il pensiero di Proclo in Bertoldo di Moosburg“, in Arkete. Rivista di studi filosofici 1(2005), S.51-67. 